\section{OPEN ACCESS}

Edited by:

Hasan Zaki,

University of Texas Southwestern Medical Center, United States

Reviewed by:

Hector Mora Montes,

University of Guanajuato, Mexico

Claudia Feriotti,

Queen's University Belfast,

United Kingdom

*Correspondence:

Patcharee Ritprajak

Patcharee.R@chula.ac.th

Specialty section:

This article was submitted to Microbes and Innate Immunity,

a section of the journal

Frontiers in Cellular and

Infection Microbiology

Received: 28 May 2020 Accepted: 27 November 2020 Published: 22 January 2021

Citation:

Dinh TTH, Tummamunkong $P$,

Padungros $P$, Ponpakdee $P$,

Boonprakong L, Saisorn W,

Leelahavanichkul A, Kueanjinda $P$ and

Ritprajak P (2021) Interaction Between

Dendritic Cells and Candida krusei

$\beta$-Glucan Partially Depends on

Dectin-1 and it Promotes High

IL-10 Production by T Cells.

Front. Cell. Infect. Microbiol. 10:566661.

doi: $10.3389 /$ fcimb.2020.566661

\title{
Interaction Between Dendritic Cells and Candida krusei $\beta$-Glucan Partially Depends on Dectin-1 and It Promotes High IL-10 Production by $\mathbf{T}$ Cells
}

Truc Thi Huong Dinh ${ }^{1,2}$, Phawida Tummamunkong ${ }^{2}$, Panuwat Padungros ${ }^{3}$,
Pranpariya Ponpakdee $^{3}$, Lawan Boonprakong ${ }^{4}$, Wilasinee Saisorn ${ }^{5}$,
Asada Leelahavanichkul ${ }^{5}$, Patipark Kueanjinda ${ }^{6}$ and Patcharee Ritprajak ${ }^{2,7 *}$

${ }^{1}$ Medical Microbiology Interdisciplinary Program, Graduate School, Chulalongkorn University, Bangkok, Thailand, ${ }^{2}$ Research Unit in Integrative Immuno-Microbial Biochemistry and Bioresponsive Nanomaterials, Department of Microbiology, Faculty of Dentistry, Chulalongkorn University, Bangkok, Thailand, ${ }^{3}$ Green Chemistry for Fine Chemical Productions STAR, Department of Chemistry, Faculty of Science, Chulalongkorn University, Bangkok, Thailand, ${ }^{4}$ Oral Biology Research Center, Faculty of Dentistry, Chulalongkorn University, Bangkok, Thailand, ${ }^{5}$ Translational Research in Inflammation and Immunology Research Unit (TRIRU), Department of Microbiology, Faculty of Medicine, Chulalongkorn University, Bangkok, Thailand, 6 Department of Microbiology, Faculty of Medicine, Chulalongkorn University, Bangkok, Thailand, ${ }^{7}$ Department of Microbiology, Faculty of Dentistry, Chulalongkorn University, Bangkok, Thailand

Host-Candida interaction has been broadly studied during Candida albicans infection, with a progressive shift in focus toward non-albicans Candida species. C. krusei is an emerging multidrug resistant pathogen causing rising morbidity and mortality worldwide. Therefore, understanding the interplay between the host immune system and C. krusei is critically important. Candia cell wall $\beta$-glucans play significant roles in the induction of host protective immune responses. However, it remains unclear how $C$. krusei $\beta$-glucan impacts dendritic cell (DC) responses. In this study, we investigated DC maturation and function in response to $\beta$-glucans isolated from the cell walls of $C$. albicans, $C$. tropicalis, and C. krusei. These three distinct Candida $\beta$-glucans had differential effects on expression of the DC marker, CD11c, and on DC maturation. Furthermore, bonemarrow derived DCs (BMDCs) showed enhanced cytokine responses characterized by substantial interleukin (IL)-10 production following C. krusei $\beta$-glucan stimulation. BMDCs stimulated with $C$. krusei $\beta$-glucan augmented IL-10 production by T cells in tandem with increased IL-10 production by BMDCs. Inhibition of dectin-1 ligation demonstrated that the interactions between dectin-1 on DCs and cell wall $\beta$-glucans varied depending on the Candida species. The effects of $C$. krusei $\beta$-glucan were partially dependent on dectin-1, and this dependence, in part, led to distinct DC responses. Our study provides new insights into immune regulation by $C$. krusei cell wall components. These data may be of use in the development of new clinical approaches for treatment of patients with $C$. krusei infection.

Keywords: Candida krusei, $\beta$-glucan, dendritic cells, T cells, dectin-1, immune modulation 


\section{INTRODUCTION}

Candida species are the most common causative agents of opportunistic mycoses that impose increasing burdens of morbidity and mortality. In recent decades, mucocutaneous and invasive Candida infections caused by non-albicans Candida species have increased globally as a result of the development of anti-fungal drug resistance (Colombo et al., 2017; Kontoyiannis, 2017). Candida krusei commonly causes nosocomial infections in patients with hematologic malignancies (Kim et al., 2017; Lortholary et al., 2017; Jamiu et al., 2020), as well as osteomyelitis, pneumonia, vaginitis, endophthalmitis, endocarditis, oral candidiasis, and other conditions in patients with underlying medical complications (Jamiu et al., 2020). C. krusei is an emerging multi-drug resistant pathogen: it is intrinsically resistant to fluconazole and rapidly acquires resistance to other anti-fungal drugs such as flucytosine, amphotericin B and echinocandins (Jamiu et al., 2020). Hence, C. krusei-infected individuals have high mortality rates (Kronen et al., 2017; Jamiu et al., 2020).

Carbohydrate constituents of fungal cell walls are the main pathogen-associated molecular patterns (PAMPs) that trigger both host protective immunity and pathogenic inflammatory responses. $\beta$-glucan is one of the major carbohydrate components making up the inner skeleton of the Candida cell wall, and acts as a key PAMP triggering host immune responses (Gow et al., 2011; Netea et al., 2015). Recognition of $\beta$-glucan in the Candida cell wall by the dectin-1 receptor has been shown to play a key role in protective immunity and subsequent fungal eradication (Taylor et al., 2007; Gow et al., 2011). Moreover, levels of serum $\beta$-glucan shed from the cell wall were correlated with the clinical outcomes of patients with invasive candidiasis (Sims et al., 2012; Giacobbe et al., 2015). Therefore, circulating $\beta$-glucans may directly interact with immune cells and induce either protective immunity or pathologic inflammatory responses.

Dendritic cells (DCs) are antigen-presenting cells that play a key role in Candida recognition, phagocytosis, and killing (Newman and Holly, 2001; Netea et al., 2004). Interactions between invading fungi and DCs via pattern-recognition receptors (PRRs) such as C-type lectin receptors and Toll-like receptors (TLRs) allow DCs to develop functional versatility, which determines the fate of adaptive immune responses (Wuthrich et al., 2012). Engagement of dectin-1 on DCs leads to Syk activation and subsequent C. albicans clearance (Skrzypek et al., 2009). Dectin-1 is also required for DC discrimination of yeast and hyphae and to induce Th17-mediated anti-Candida immunity through an interleukin (IL)-6-dependent mechanism (Kashem et al., 2015). Furthermore, recent studies demonstrated that differential $\beta$-glucan exposure on the cell walls of various Candida species resulted in distinct immune responses (Chen et al., 2019; Thompson et al., 2019).

At present, little is known regarding the immune response to C. krusei, and the interplay between C. krusei $\beta$-glucan and DCs is poorly understood. In this study, we investigated the effects of C. krusei, C. albicans, and C. tropicalis $\beta$-glucans on DC activation and subsequent $\mathrm{T}$ cell responses. We also observed the differential dectin-1-mediated DC responses to the $\beta$-glucans of three distinct Candida species. Our data provide insights into $\beta$-glucan-DC interactions and subsequent regulation of $\mathrm{T}$ cell immunity.

\section{MATERIALS AND METHODS}

\section{Animals and Ethics Statement}

Female C57BL/6s (5-6 weeks old) were purchased from Nomura Siam International Co., Ltd., Bangkok, Thailand. All animal procedures were performed in accordance with the guidelines and approved by the Chulalongkorn University Institutional Animal Care and Use Committee (IACUC) (Animal protocol 19-33-010 and 031/2561).

\section{Candida Strains and Culture}

C. albicans strain SC5314 was used in this study as its cell wall $\beta$ glucans have been well characterized (Lowman et al., 2003a; Lowman et al., 2014). C. tropicalis strain ATCC 750 and C. krusei strain ATCC 6258 were selected because these reference strains are used for quality control and antifungal drug susceptibility testing. All Candida yeasts were grown in Yeast Peptone Dextrose (YPD) broth (HiMedia Laboratories, Mumbai, India) at $30^{\circ} \mathrm{C}$ for $6-8 \mathrm{~h}$ with $180 \mathrm{rpm}$ shaking. Subsequently, the yeast cultures were diluted to an $\mathrm{OD}_{600}$ of 0.1 and grown in $1.2 \mathrm{~L}$ of YPD medium at $30^{\circ} \mathrm{C}$ for $13 \mathrm{~h}$ with $150 \mathrm{rpm}$ shaking. Under these culture conditions, all Candida species grow as budding yeast-like cells (Katiyar and Edlind, 2001; Kadosh and Johnson, 2005; Suzuki et al., 2006). The morphologies of all Candida yeasts were assessed using bright field microscopy (Olympus BX50, Tokyo, Japan).

\section{Cell Wall $\beta$-Glucan Extraction}

The protocols for Candida $\beta$-glucan extraction, depyrogenation and sterilization were kindly provided by East Tennessee State University, Johnson City, TN, USA. (Lowman et al., 2003a; Lowman et al., 2014). Briefly, Candida cell walls were first boiled at $100^{\circ} \mathrm{C}$ in $0.1 \mathrm{~N} \mathrm{NaOH}$ for $15 \mathrm{~min}$ (three extractions). The harvested residues were next boiled at $100^{\circ} \mathrm{C}$ in $2 \mathrm{~N} \mathrm{H}_{3} \mathrm{PO}_{4}$ for $15 \mathrm{~min}$ (three extractions), and the resulting residues were then boiled at $100^{\circ} \mathrm{C}$ in acidic ethanol $\left(1 \% \mathrm{v} / \mathrm{v}\right.$ of $\mathrm{H}_{3} \mathrm{PO}_{4}$ in absolute ethanol) for $15 \mathrm{~min}$ (three extractions) followed by neutralization to $\mathrm{pH}$ 7.0. The glucans were washed three times with endotoxin-free water. The glucans isolated using this procedure are water-insoluble microparticulates. Isolated $\beta$ glucans were depyrogenated in $250 \mathrm{mM} \mathrm{NaOH}$ and subsequently neutralized to $\mathrm{pH} 7.0$ in $250 \mathrm{mM} \mathrm{H}_{3} \mathrm{PO}_{4}$. The $\beta$ glucans were washed in endotoxin-free water three times and sterilized by autoclaving at $121^{\circ} \mathrm{C}$ under 15 psi of pressure for $30 \mathrm{~min}$. The amount of extracted $\beta$-glucans were used as dry weight. $\beta$-glucans were heat-dried at $50-60^{\circ} \mathrm{C}$, and the dried glucans were weighted. The concentrations of $\beta$-glucans in all experiment are used as dry weight per volume. All yeast culture and $\beta$-glucan extraction procedures were performed using 
endotoxin free water and containers. The three batches of extracted glucans were pooled and used for all the experiments.

\section{Scanning Electron Microscopy}

Candida $\beta$-glucans were fixed in $2.5 \%$ glutaraldehyde in $0.1 \mathrm{M}$ phosphate buffer at $\mathrm{pH} 7.2$ for $18 \mathrm{~h}$ at $4^{\circ} \mathrm{C}$. The fixed $\beta$-glucans were washed with sterile deionized water and were air dried. The $\beta$-glucans were then processed for ultra-thin gold coating (JFC1200, JEOL, Peabody, MA, USA). The specimens were observed by a scanning electron microscopy (Quanta250, FEI, Hillsboro, OR, USA) with 10,000x magnifications.

\section{Generation of Bone Marrow-Derived Dendritic Cells}

DCs were isolated from murine bone marrow as described previously (Inaba et al., 2009; Nguyen et al., 2018). Briefly, bone marrow cells were isolated from femurs and tibias of mice. The cells $\left(1 \times 10^{6}\right.$ per $\left.1 \mathrm{ml}\right)$ were seeded in 24 -well plates and cultured in RPMI 1640 (GIBCO, Thermo Fisher Scientific, New York, NY, USA) containing $10 \%$ heat-inactivated fetal bovine serum (GIBCO), $0.2 \mathrm{mM}$ Glutamax (GIBCO), $100 \mathrm{U} / \mathrm{ml}$ penicillin, $100 \mathrm{mg} / \mathrm{ml}$ streptomycin (GIBCO), $10 \mathrm{ng} / \mathrm{ml}$ recombinant murine granulocyte-macrophage colony-stimulating factor (Peprotech, Rocky Hill, NJ, USA), and $10 \mathrm{ng} / \mathrm{ml}$ recombinant murine IL-4 (Peprotech). The cells were incubated at $37^{\circ} \mathrm{C}$ under a humidified atmosphere containing $5 \% \mathrm{CO}_{2}$ for 7 days. Half of the media volume was replaced every 2 days.

\section{Bone Marrow-Derived Dendritic Cell Stimulation With Candida $\beta$-Glucans}

BMDCs were stimulated with $\beta$-glucans isolated from $C$. albicans, C. tropicalis, and C. krusei at concentrations of 12.5, 25 , and $50 \mu \mathrm{g} / \mathrm{ml}$ for $24 \mathrm{~h}$ and $48 \mathrm{~h}$. Unstimulated BMDCs were used as negative controls. Culture supernatants were collected for cytokine measurement and cells were harvested for evaluation of DC maturation marker expression.

\section{Dectin-1 Blockade}

BMDCs were pre-treated with $25 \mu \mathrm{g} / \mathrm{ml}$ of a dectin- 1 antagonist (soluble whole glucan particles; InvivoGen, San Diego, CA, USA) for $2 \mathrm{~h}$ and then $25 \mu \mathrm{g} / \mathrm{ml}$ of $\beta$-glucans isolated from C. albicans, $C$. tropicalis, and C. krusei were added to the culture. For comparison dectin-1 blockade, BMDCs were stimulated with $25 \mu \mathrm{g} / \mathrm{ml}$ of Candida $\beta$-glucans in the absence of dectin- 1 antagonists. As a negative control, BMDCs were either untreated or pre-treated with dectin-1 antagonist. At $24 \mathrm{~h}$ and $48 \mathrm{~h}$ post-stimulation, culture supernatants were collected for cytokine measurement and cells were harvested for assessment of DC maturation marker expression.

\section{Syk Inhibition}

BMDCs were pre-treated with $1 \mu \mathrm{M}$ of Syk inhibitor (InvivoGen) for $30 \mathrm{~min}$ prior to treatment of $25 \mu \mathrm{g} / \mathrm{ml}$ of $\beta$-glucans isolated from C. albicans, C. tropicalis, and C. krusei. For comparison of dectin-1 blockade, BMDCs were stimulated with $25 \mu \mathrm{g} / \mathrm{ml}$ of Candida $\beta$-glucans in the absence of dectin- 1 antagonists. As a negative control, BMDCs were either untreated or pre-treated with dectin- 1 antagonist. At $24 \mathrm{~h}$ and $48 \mathrm{~h}$ post-stimulation, culture supernatants were collected for cytokine measurement and cells were harvested for assessment of DC maturation marker expression.

\section{Flow Cytometry Analysis}

To evaluate BMDC maturation and inhibitory phenotype, BMDCs were stained with fluorophore-tagged monoclonal antibodies against mouse CD11c (N418), mouse CD40 (3/23), mouse CD80 (16-10A1), mouse CD86 (CL-1), mouse I-A/I-E (MHC class II) (M5/114.152), PD-L1 (MIH7), PD-L2 (TY25), CD206 (C068C2), and dectin-1 (RH1). For T cell assay, LN cells and splenocytes were stained with fluorophore-tagged monoclonal antibodies against mouse mouse CD3 (145-2C11), CD4 (GK1.5), mouse CD25 (PC61), and mouse/human FoxP3 (FJK-16s). Prior to staining with specific antibodies, the cells were incubated with Fc block (purified anti-mouse CD16/32) to reduce non-specific binding. All antibodies were obtained from BioLegend (San Diego, CA, USA) except for the anti-FoxP3 antibody, which was obtained from eBioscience (San Diego, CA, USA). The stained cells were assessed by flow cytometry (CytoFLEX, Beckman Coulter, San Diego, CA, USA) and the data were analyzed using Kaluza Flow Analysis Software (Beckman Coulter). For flow cytometry acquisition, the live cells of all samples were acquired at 20,000 cells/sample. Accordingly, the same electronic gate was applied to all sample for flow cytometry acquisition and analyses.

\section{In Vitro Dendritic Cell and T Cell Co-Culture Assay}

BMDCs were stimulated with $25 \mu \mathrm{g} / \mathrm{ml}$ of Candida $\beta$-glucans for $24 \mathrm{~h}$ and the cells were then washed with RPMI medium twice. The BMDCs $\left(1 \times 10^{5}\right.$ cells) were co-cultured with T cells $\left(1 \times 10^{6}\right)$ isolated from spleens of intact mice using immunomagnetic beads (Pan T Cell Isolation Kit II, mouse; Miltenyi Biotec, San Diego, CA, USA) at a DC:T cell ratio of 1:10 in the presence of 30 $\mathrm{ng} / \mathrm{ml}$ of soluble anti-CD3 antibody (145-2C11, Biolegend) in 48-well plates (Clement et al., 1985; Li and Kurlander, 2010). After $72 \mathrm{~h}$, the culture supernatants were collected and the cells were stained for CD4, CD25 and FoxP3.

\section{In Vivo Immunization and Ex Vivo Re-Stimulation Assay}

We performed subcutaneous immunization in the scruff of the neck with a mixture of $2 \mathrm{mg}$ of $C$. albicans or $C$. krusei $\beta$-glucans and $30 \mu \mathrm{g}$ of oval chicken albumin (OVA, Grade V, Sigma) in $200 \mu \mathrm{l}$ PBS at day 0 and day 7. On day 14, draining lymph nodes (LNs) (cervical and brachial LNs) were excised from the mice and the LNs were digested with 300 units $/ \mathrm{ml}$ Collagenase IV (GIBCO) and 20 units $/ \mathrm{ml} \mathrm{DNase} \mathrm{I} \mathrm{(Sigma)} \mathrm{at} 37^{\circ} \mathrm{C}$ with $200 \mathrm{rpm}$ shaking for $45 \mathrm{~min}$. The LN cells were washed twice with RPMI containing $10 \%$ heat-inactivated FBS and pen/strep. The LNs were then seeded at $2 \times 10^{6}$ cells in $500 \mu \mathrm{l}$ of culture medium per well in 48-wells plate and stimulated with $200 \mu \mathrm{g} / \mathrm{ml}$ OVA. Culture supernatants were collected at $48 \mathrm{~h}$ post-stimulation for ELISA. The cells were harvested at $72 \mathrm{~h}$ post-stimulation and were then stained for CD3, CD4, CD25 and FoxP3. 


\section{In Vivo Candida krusei Infection and Ex Vivo Re-Stimulation}

The mice were divided into three groups (PBS, low dose, and high dose of C. krusei). Prior to C. krusei infection, dexamethasone $(0.1 \mathrm{mg} / \mathrm{g}$ of body weight; Dexton-Vet, T.P. Drug laboratories (1969), Bangkok, Thailand) were intraperitoneally injected to the mice on day $-3,-2,-1$, and 5 to induced immunosuppression (Jacobsen et al., 2010). At day 0, mice were intravenously inoculated with $1 \times 10^{6}$ and $5 \times 10^{6}$ of $C$. krusei yeast cells in $100 \mathrm{ul}$ of PBS. On day 7 post-infection, blood serum and spleens were harvested from the mice. Spleens were mechanically disrupted and treated with RBC lysis buffer $(8.02 \mathrm{~g}$ $\mathrm{NH} 4 \mathrm{Cl}, 0.84 \mathrm{~g} \mathrm{NaHCO} 3$, and $0.37 \mathrm{~g}$ EDTA in $1 \mathrm{~L}$ sterile deionized water) to remove red blood cells. Splenocytes were then washed in RPMI medium containing 10\% heat-inactivated FBS and pen/strep Then $2 \times 10^{6}$ cells of splenocytes were stained for CD3, CD4, CD25, and FoxP3.

For ex vivo re-stimulation, purified anti-CD3 antibody (BioLegend, cat \# 145-2C11) were immobilized on 24-well plat. Briefly, $10 \mu \mathrm{g} / \mathrm{ml}$ of purified anti-CD3 in $200 \mu \mathrm{l}$ of Dulbecco's Phosphate Buffered Saline (DPBS) were coated on the plate at $4^{\circ} \mathrm{C}$ overnight. Prior to cell seeding, the anti-CD3 solution were removed and the coated wells were rinsed with culture medium twice. Then, the splenocyted were seeded at the concentration of $4 \times 10^{6}$ cells/well in $1 \mathrm{ml}$ of culture medium (RPMI1640 supplemented with $10 \%$ of heat-inactivated FBS, $2 \mathrm{mM} \mathrm{L-}$ glutamax, $100 \mathrm{U} / \mathrm{ml}$ of penicillin, $100 \mathrm{U} / \mathrm{mg}$ of streptomycin, and $0.055 \mathrm{mM} 2$-mercaptoethanol). 48-h post-stimulation, culture supernatants were collected for cytokine measurements and the cells were harvested and stained for CD3, CD4, CD25, and FoxP3.

\section{Cytokine Quantification}

Cytokines [interferon (IFN)- $\gamma$, IL-1 $\beta$, IL-2, IL-6, IL-12, IL-17, IL23 , IL-10, and tumor necrosis factor (TNF)- $\alpha$ ] in the culture supernatants of BMDCs and cytokines IFN- $\gamma$, IL-17, and IL-10 in the serum and culture supernatants of LN cells and splenocytes were quantified by sandwich ELISA following the manufacturer's instructions. All ELISA kits were purchased from Biolegend, except the IL-23 ELISA kit, which was obtained from eBioscience. The absorbance was measured at $450 \mathrm{~nm}$ using a microplate reader (EPOCH2C, BioTek).

\section{Statistical Analysis}

All data were presented as means \pm standard deviations. Sample sizes are indicated in each figure legend. The data were analyzed using one-way ANOVA with post-hoc Tukey HSD test in SPSS 22 software (IBM, New York, NY, USA). Values of $p<0.05$ were considered statistically significant.

\section{RESULTS}

\section{Morphology and Structure Analysis of Candida $\beta$-Glucans}

First, $\beta$-glucans of $C$. albicans, C. tropicalis, and C. krusei were morphologically characterized by scanning electron microscopy
(SEM) (Figure 1). $\beta$-glucans of $C$. albicans were similar to $C$. tropicalis in terms of size and shape (Figures 1A, B, respectively) The average size of $C$. albicans $\beta$-glucans was $4-5 \mu \mathrm{M}$ and the average size of $C$. tropicalis $\beta$-glucans was $4-6 \mu \mathrm{M}$. Both $C$. albicans and $C$. tropicalis $\beta$-glucans formed oval shape. In addition, $\beta$-glucans of these two Candida species appeared as a dense fine speckled pattern. On the other hand, the morphology of $C$. krusei $\beta$-glucans was drastically different from the other two as they formed rod shape and large in size (average size is $7-10$ $\mu \mathrm{M})$, and surface of the $\beta$-glucans exhibited a course speckled pattern (Figure 1C).

In addition to morphological appearance, NMR analysis was performed to characterize Candida $\beta$-glucan structure. NMR characterizations of Candida $\beta$-glucans were challenging due to their low solubilities in all deuterated solvents (Padungros et al., 2012; Padungros et al., 2014). The addition of deuterated trifluoroacetic acid $\left(\mathrm{TFA}-\mathrm{d}_{1}\right)$ slightly enhanced the solubility. More importantly, TFA-d shifted all exchangeable protons on the hydroxyl groups of Candida $\beta$-glucans toward the downfield region, thus reducing overlapped protons signals on the pyranose rings. Characterization of $C$. albicans $\beta$-glucan and $C$. tropicalis $\beta$-glucan prove difficult due to their low solubilities in DMSO- $\mathrm{d}_{6}$ despite increasing temperature up to $60^{\circ} \mathrm{C}$. Nevertheless, the ${ }^{1} \mathrm{H}$ NMR spectra of both $C$. albicans $\beta$-glucan and C. tropicalis $\beta$ glucan were suggested that they were $\beta$ - $(1,3)$-glucan with $\beta$ $(1,6)$-branching (Supplementary Figure S1 and S2) (Lowman et al., 2003b; Sukumaran et al., 2010; Lowman et al., 2014). For the $C$. krusei $\beta$-glucan, satisfying NMR spectra were obtained by performing measurement at room temperature. ${ }^{1} \mathrm{H}$ NMR signals of anomeric proton ( $\mathrm{H}-1)$ was identified at $\delta 4.56 \mathrm{ppm}, \mathrm{H}-6$ was at $\delta 3.74$ ppm, $\mathrm{H}-3 / \mathrm{H}-6$ ' were at $\delta 3.52-3.46 \mathrm{ppm}$, and $\mathrm{H}-2 / \mathrm{H}-5 /$ $\mathrm{H}-4$ were at $\delta 3.33-3.23 \mathrm{ppm}$ (Supplementary Figure S3). These signals were corresponded to $\beta$ - $(1,3)$-glucan structure. Surprisingly, characteristic $\beta$ - $(1,6)$-glucan side chain signals at $4.24 \mathrm{ppm}$ and $4.08 \mathrm{ppm}$ were not observed (Kono et al., 2017). The simplicity of the ${ }^{1} \mathrm{H}$ NMR signals indicated that the $C$. krusei $\beta$-glucan was a highly homogeneous $\beta$ - $(1,3)$-glucan without $\beta$ (1,6)-branching. ${ }^{13} \mathrm{C}$ NMR signals were also supported unbranched $\beta$-(1,3)-glucan structure and identified as following; $\beta$-anomeric carbon (C-1), C-3, C-5, C-2, C-4, and C-6 were at $104.3,87.4,77.5,74.0,69.6$, and $62.0 \mathrm{ppm}$ (Supplementary Figure S4) (Gerbst et al., 2013). The assignments of $C$. krusei $\beta$-glucan were further confirmed by COSY (Supplementary Figure S5) and HSQC (Figure 2) experiment which provided connectivity between ${ }^{1} \mathrm{H}-\mathrm{C}-\mathrm{C}-{ }^{1} \mathrm{H}$ (three-bond coupling) and ${ }^{1} \mathrm{H}-{ }^{13} \mathrm{C}$ (one-bond coupling) on the $\beta$-(1,3)-glucan, respectively.

\section{Effects of Candida $\beta$-glucans on Dendritic Cell Viability and CD11c Expression}

To determine any potential contamination with bacterial endotoxin LPS during $\beta$-glucan preparation, we pre-treated our $\beta$-glucans with polymyxin $\mathrm{B}$, a potent LPS neutralizer (Cardoso et al., 2007), before BMDC stimulation followed by an assessment of DC maturation marker expression (CD40, CD80, CD86, MHC class II) and inflammatory cytokine levels 
A C. albicans

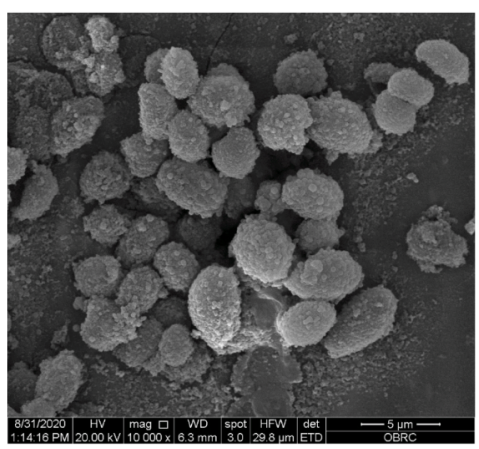

B C. tropicalis

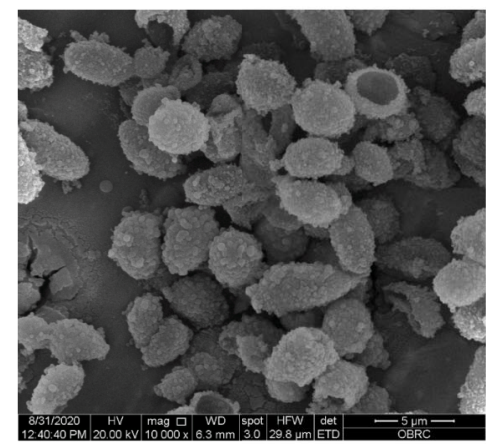

C C. krusei

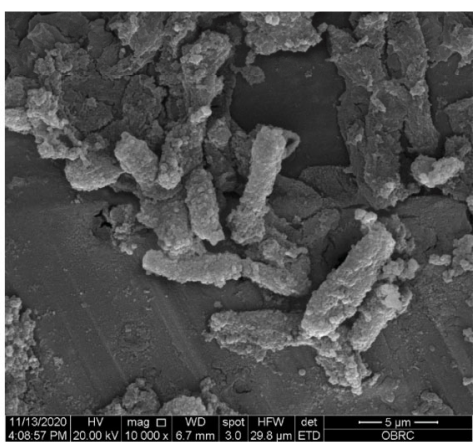

FIGURE 1 | Morphology and size of Candida $\beta$-glucans. $\beta$-glucans of (A) Candida albicans, (B) Candida tropicalis, and (C) Candida krusei were observed by scanning electron microscopy (SEM) with 10,000x magnification.

(IL-6 and TNF- $\alpha$ ) (Supplementary Figures S6-S7). The results showed no significant difference in the expression of DC maturation markers and inflammatory cytokines between untreated and polymyxin B-treated groups, indicating that there was no endotoxin contamination in our $\beta$-glucans.

Candida $\beta$-glucans are PAMPs, which may transduce signals via PRRs and lead to cell death (Takeuchi and Akira, 2010; Kingeter and Lin, 2012). Therefore, we first examined DC viability in response to Candida $\beta$-glucan stimulation. BMDCs were stimulated with various concentrations of $\beta$-glucans isolated from the cell walls of $C$. albicans, $C$. tropicalis, and $C$. krusei for $24 \mathrm{~h}$ and $48 \mathrm{~h}$, and the cell viability was determined by MTT assay (Supplementary Figure S8). At all doses tested, $\beta$ glucans from these three distinct Candida species showed no major effects on DC viability at both $24 \mathrm{~h}$ and $48 \mathrm{~h}$ (Supplementary Figures S8A and S8B, respectively) poststimulation. The $\beta$-glucans of all Candida species had similar effects on DC viability. However, DC viability at $48 \mathrm{~h}$ showed a decreasing trend when BMDCs were stimulated with the highest concentration $(50 \mu \mathrm{g} / \mathrm{ml})$ of C. albicans and C. krusei $\beta$-glucans (Supplementary Figure S8B).

We next evaluated DC proportions in Candida $\beta$-glucanstimulated bone marrow cells by flow cytometry analysis of the
DC marker, CD11c (Figure 3). CD11 $\mathrm{c}^{+}$cells were gated and identified as DCs (Supplementary Figures S9A and S10A). At $24 \mathrm{~h}$ post-BMDC stimulation, all doses of $C$. albicans and $C$. tropicalis $\beta$-glucans did not alter the DC proportion, while $C$. krusei $\beta$-glucan at 25 and $50 \mu \mathrm{g} / \mathrm{ml}$ slightly reduced the percentage of $\mathrm{CD}_{11 \mathrm{c}^{+}}$cells compared with that among unstimulated BMDCs (Figure 3A, left panel). Furthermore, the

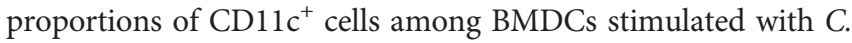
krusei $\beta$-glucan were significantly different from the proportions among BMDCs stimulated with C. albicans and C. tropicalis $\beta$ glucans (Supplementary Figure S12A, left panel). At 48 h poststimulation, the percentages of $\mathrm{CD}_{11 \mathrm{c}^{+}}$cells among BMDCs stimulated with 25 and $50 \mu \mathrm{g} / \mathrm{ml}$ of all Candida $\beta$-glucans were reduced compared with unstimulated BMDCs (Figure 3A, right panel). However, a difference in DC proportion was not observed among BMDCs stimulated with different Candida $\beta$-glucans (Supplementary Figure S12A, right panel). CD11c expression levels of Candida $\beta$-glucan-stimulated BMDCs were also determined using histogram analyses of mean fluorescence intensity (MFI) (Figure 3B and Supplementary Figure S11). At $24 \mathrm{~h}$ post-stimulation, CD11c expression levels of BMDCs stimulated with $C$. albicans and C. tropicalis $\beta$-glucans were not clearly altered. By contrast, stimulation with C. krusei $\beta$-glucans 


\section{NMR analysis}

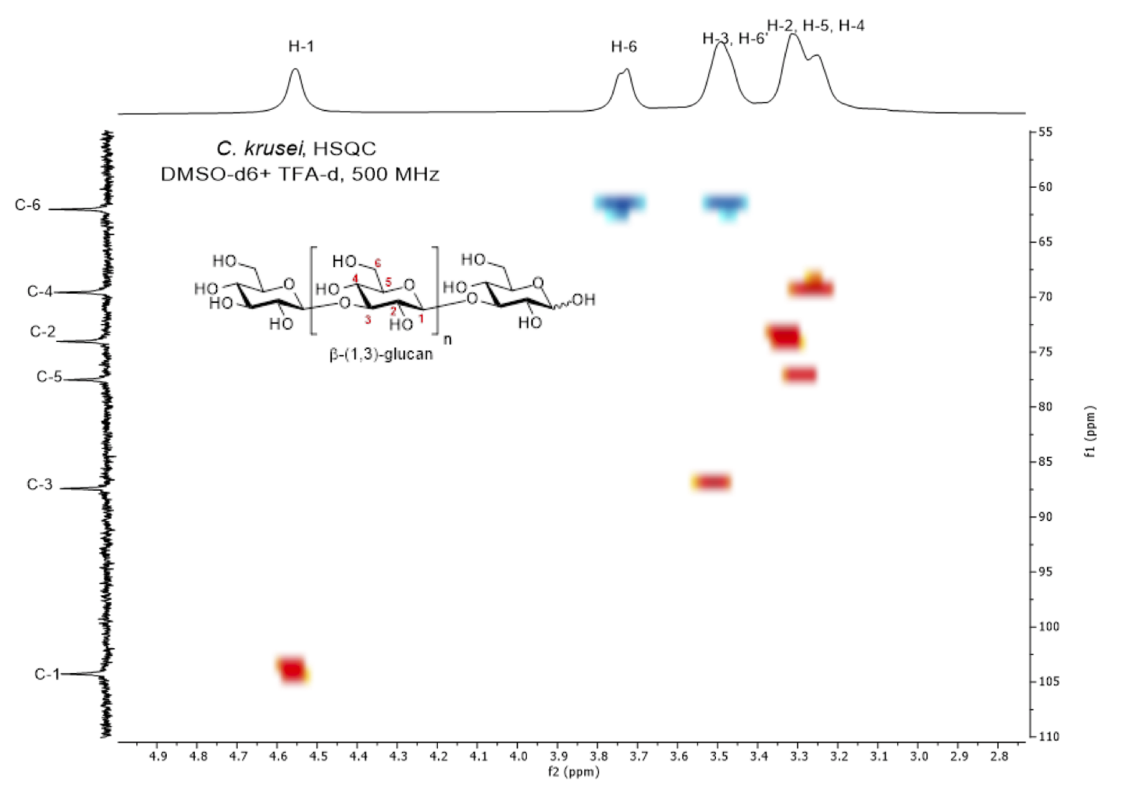

FIGURE 2 | HSQC spectrum of C. krusei $\beta$-glucan $\left(500 \mathrm{MHz}\right.$, DMSO- $d_{6}+$ TFA- $\left.d_{1}\right)$. C. krusei $\beta$-glucan $50 \mathrm{mg}$ was dissolved in DMSO- $d_{6}(2.07 \mathrm{ml})$ and TFA- $d_{1}$ $(0.11 \mathrm{ml})$ then $0.5 \mathrm{~mL}$ of the solution was withdrawn to perform the HSQC experiment with $500 \mathrm{MHz}$ NMR spectrometer at room temperature. The spectrum indicated a highly homogeneous $\beta$-(1,3)-glucan without $\beta$-(1,6)-branching.

(25 and $50 \mu \mathrm{g} / \mathrm{ml}$ ) significantly diminished CD11c expression on BMDCs compared with expression on unstimulated BMDCs. CD11c expression in C. krusei $\beta$-glucan-stimulated BMDCs was markedly lower than that in $C$. albicans and C. tropicalis $\beta$ glucan-stimulated BMDCs (Figure 3B, left panel). At 48 h poststimulation, the expression of CD11c was significantly reduced on BMDCs stimulated with 25 and $50 \mu \mathrm{g} / \mathrm{ml}$ of all Candida $\beta$ glucans. However, $\beta$-glucans of distinct Candida species showed no differential effect on CD11c expression (Figure 3B, right panel). Our data indicated that $\beta$-glucans from C. albicans, $C$. tropicalis, and C. krusei did not significantly affect DC viability and DC proportion. However, $\beta$-glucan from C. krusei downregulated CD11 expression on BMDCs.

\section{Candida krusei $\beta$-Glucans Had a Differential Impact on Dendritic Cell Maturation}

Next, the effects of Candida $\beta$-glucans on DC maturation were evaluated. BMDCs were activated with various doses of Candida $\beta$-glucans for $24 \mathrm{~h}$ and $48 \mathrm{~h}$, and expression of the DC maturation markers, CD40, CD80, CD86, and MHC class II, were determined by flow cytometry. First, the phenotypes of CD $11 \mathrm{c}^{+}$DCs were assessed using dot plot analyses (Supplementary Figure S12). The proportions of $\mathrm{CD}_{4} 0^{+}$, $\mathrm{CD}^{+} 0^{+}, \mathrm{CD} 86^{+}$, and $\mathrm{MHC}$ class $\mathrm{II}^{+}$subpopulations of $\mathrm{CD} 11 \mathrm{c}^{+}$ cells were analyzed (Supplementary Figure 9B and 10B). BMDCs underwent maturation upon stimulation with all
Candida $\beta$-glucans and the percentages of $\mathrm{CD} 40^{+}, \mathrm{CD} 80^{+}$, $\mathrm{CD}^{+} 6^{+}$, and $\mathrm{MHC}$ class $\mathrm{II}^{+}$cells were notably enhanced at both $24 \mathrm{~h}$ and $48 \mathrm{~h}$ post-stimulation (Supplementary Figure S12). BMDCs stimulated with three distinct Candida $\beta$-glucans showed similar proportions of $\mathrm{CD} 40^{+}$cells at both time points (Supplementary Figure S12A). At $24 \mathrm{~h}$ post-stimulation, the percentages of $\mathrm{CD}^{+} 0^{+}$cells (Supplementary Figure S12B, left panel) and MHC class $\mathrm{II}^{+}$cells (Supplementary Figure S12D, left panel) among C. krusei $\beta$-glucan-stimulated BMDCs were significantly lower than those among $C$. albicans and C. tropicalis $\beta$-glucan-stimulated BMDCs. There were changes observed in the $\mathrm{CD}^{+} 0^{+}$subpopulation at $48 \mathrm{~h}$ post-stimulation: the proportion of $\mathrm{CD} 80^{+}$cells among all BMDCs was reduced, and the $\mathrm{CD}^{+} 0^{+}$cell proportion among BMDCs stimulated with $C$. albicans $\beta$-glucan was lower than that among BMDCs stimulated with C. tropicalis and C. krusei $\beta$-glucans (Supplementary Figure S12B, right panel). No difference in $\mathrm{CD} 86^{+}$cell proportion among stimulated BMDCs was observed at $24 \mathrm{~h}$ (Supplementary Figure S12C, left panel), but the $\mathrm{CD}^{+} 6^{+}$cell proportion among C. krusei $\beta$-glucan-stimulated BMDCs was higher than that among $C$. albicans and $C$. tropicalis $\beta$-glucanstimulated BMDCs at $48 \mathrm{~h}$ post-stimulation (Supplementary Figure S12C, right panel). Although Candida $\beta$-glucans seemed to have differential effects on the proportions of mature DCs, only slight differences were observed.

The expression levels of maturation markers on CD11 ${ }^{+}$cells at $24 \mathrm{~h}$ and $48 \mathrm{~h}$ post-stimulation were also analyzed using 

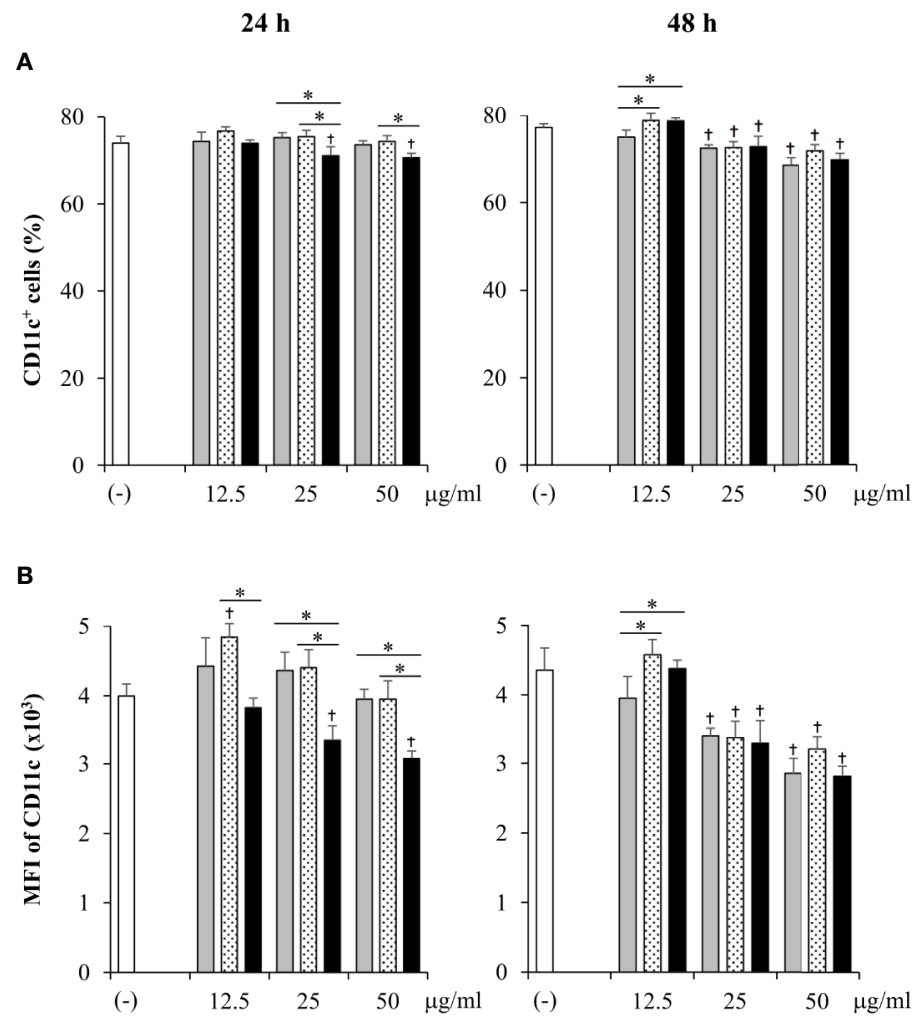

$\square C a \quad$ 다

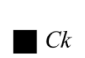

FIGURE 3 | Determination of CD11 ${ }^{+}$cell proportion and CD11c expression in bone-marrow derived dendritic cells (BMDCs) stimulated with Candida $\beta$-glucans. BMDCs were stimulated with 12.5, 25, and $50 \mu \mathrm{g} / \mathrm{ml}$ of $\beta$-glucans isolated from C. albicans, C. tropicalis, and C. krusei for $24 \mathrm{~h}$ and $48 \mathrm{~h}$. Cells were analyzed by flow cytometry. (A) The percentages of CD11 $\mathrm{C}^{+}$cells were assessed using a dot pot analysis. (B) The geometric mean fluorescence intensity (MFI) of CD11c was determined using a histogram analysis. $n=5$; data are representative of two independent experiments. ${ }^{\dagger} p<0.05$ compared with unstimulated BMDCs, ${ }^{*} p<0.05$. (-), unstimulated BMDCs; Ca, C. albicans; Ct, C. tropicalis; Ck, C. krusei.

histogram analyses of MFI values (Supplementary Figures S13 and S14). The effects of Candida $\beta$-glucans on expression levels of DC maturation markers were more apparent (Figure 4). Consistently, all markers were markedly upregulated on Candida $\beta$-glucan-stimulated BMDCs (Figure 4). The expression levels of CD40, CD80, and MHC class II on Candida $\beta$-glucan-stimulated BMDCs at both time points (Figures 4A, B, D) corresponded with the proportions of cells positive for these markers (Figures 3A, B, D). At $24 \mathrm{~h}$ poststimulation, C. krusei $\beta$-glucan-stimulated BMDCs expressed lower levels of CD80 and MHC class II than C. albicans and $C$. tropicalis $\beta$-glucan-stimulated BMDCs (Figures 4B, D). By contrast, CD86 expression on C. krusei $\beta$-glucan-stimulated BMDCs was apparently higher than that on $C$. albicans and $C$. tropicalis $\beta$-glucan-stimulated BMDCs (Figure 4C).

Other DC markers, mannose receptor CD206, and programmed death-ligand 1 (PD-L1) and PD-L2, which play a role in DC immunomodulatory function (Serrano et al., 2018), were also examined in BMDCs stimulated with Candida $\beta$ glucans. Consistent to DC maturation markers, the expression levels of CD206, PD-L1, and PD-L2 in $\beta$-glucan-stimulated BMDCs were higher than in those expression in unstimulated group (Supplementary Figures S13-S15). However, there was no notable difference among Candida $\beta$-glucans on the expression of these molecules. Collectively, our findings suggested that cell wall $\beta$-glucans from distinct Candida species differentially affected DC phenotypes and maturation.

\section{Candida krusei $\beta$-Glucan Enhanced Pro-Inflammatory and Anti-Inflammatory Cytokine Production}

To compare the effects of Candida $\beta$-glucans on DC cytokine production, the levels of pro-inflammatory cytokines (TNF- $\alpha$, IL-1 $\beta$, IL-6, IL-23, IFN- $\gamma$, IL-12) and anti-inflammatory cytokines (IL-10) were quantitated by ELISA (Figure 5 and Supplementary Figure S16). At $24 \mathrm{~h}$ post-stimulation, all Candida $\beta$-glucans activated BMDCs to produce both proinflammatory and anti-inflammatory cytokines. Higher doses of Candida $\beta$-glucans induced more cytokine production (Figure 5). C. albicans and C. tropicalis $\beta$-glucans showed similar effects 


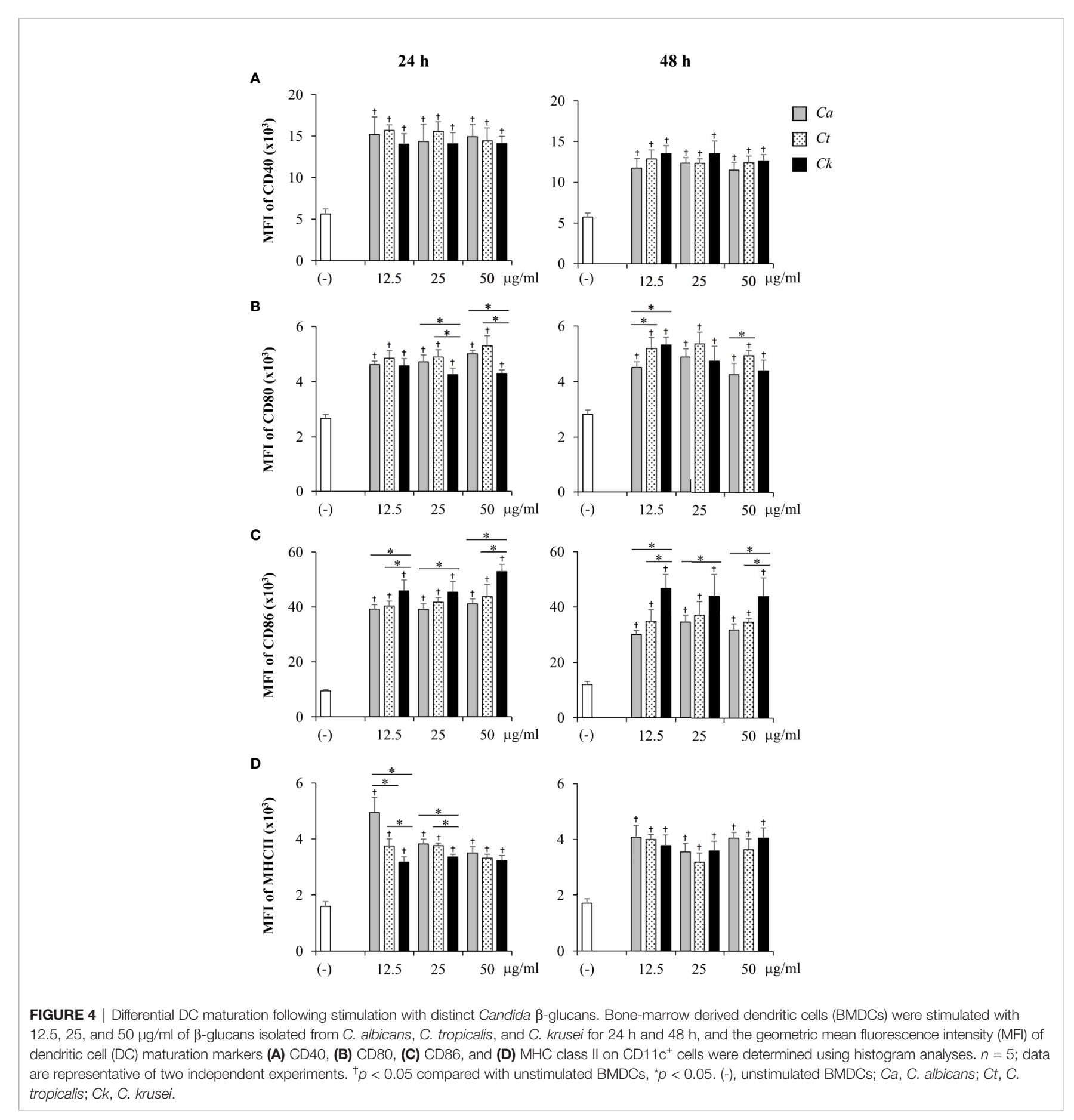

on the production of all cytokines. In contrast, $C$. krusei $\beta$-glucan augmented the production of all pro-inflammatory cytokines. Furthermore, levels of all pro-inflammatory cytokines induced by $C$. krusei $\beta$-glucan were approximately $0.5-2$ fold higher than those induced by $C$. albicans and C. tropicalis $\beta$-glucans (Figures 5A-F). Intriguingly, $C$. krusei $\beta$-glucan had a major impact on IL-10 production: the amount of IL-10 produced by BMDCs stimulated with $C$. krusei $\beta$-glucan were approximately $3-5$-fold greater than that produced by BMDCs stimulated with $C$. albicans and $C$. tropicalis $\beta$-glucans (Figure 5G). Cytokine production by Candida $\beta$-glucan-stimulated BMDCs was also determined at $48 \mathrm{~h}$ post-stimulation, and the results were consistent with the cytokine profiles at $24 \mathrm{~h}$ post-stimulation. Overall, levels of cytokines at $24 \mathrm{~h}$ and $48 \mathrm{~h}$ post-stimulation did not differ, except for a decline in IL-23 levels and a further increase in IFN- $\gamma$ levels at $48 \mathrm{~h}$ post-stimulation (Supplementary 


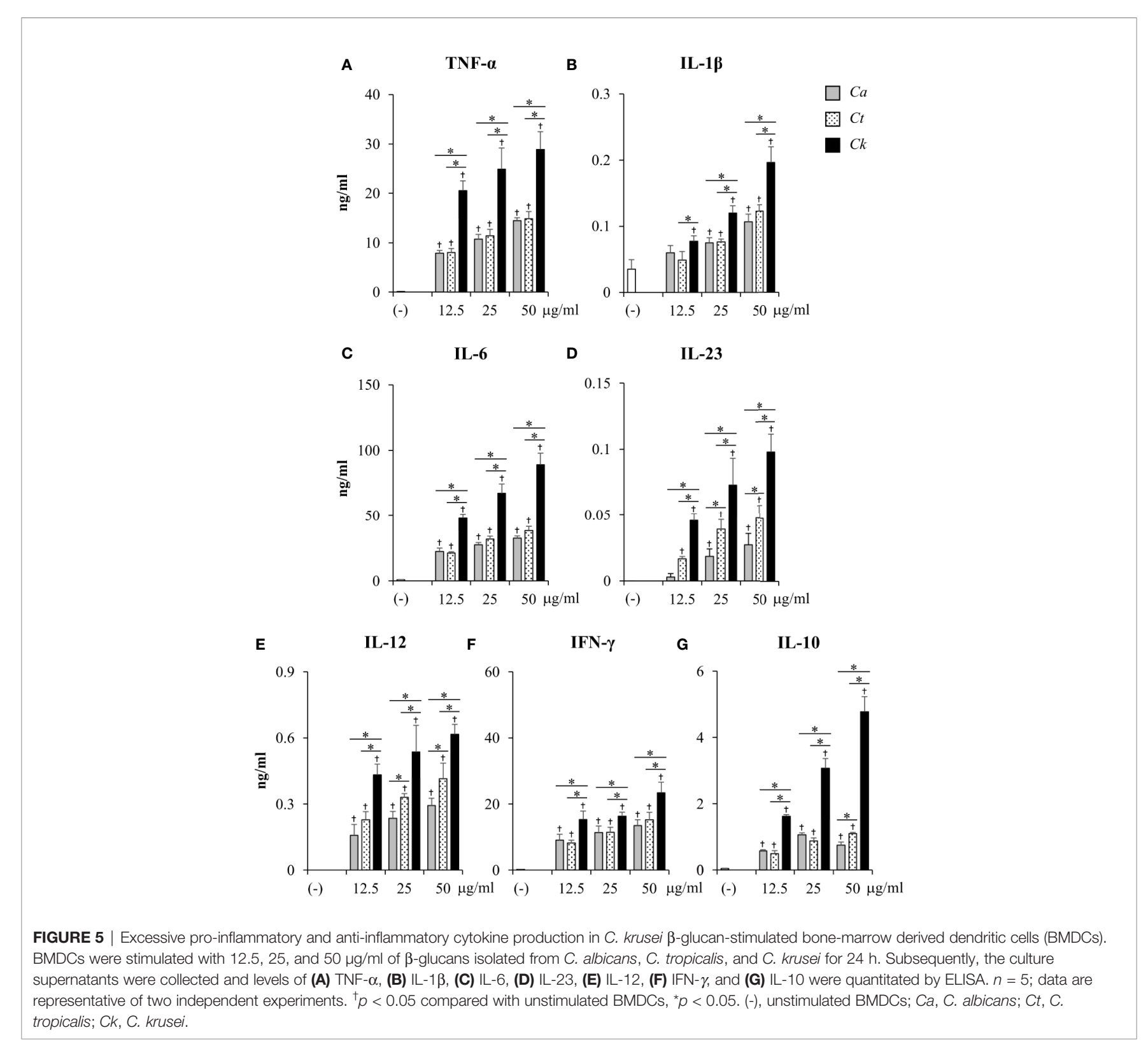

Figure S16). Among Candida $\beta$-glucans, C. krusei $\beta$-glucan was the most potent stimulus of cytokine production by DCs, especially production of the anti-inflammatory cytokine, IL-10.

\section{Candida krusei $\beta$-Glucan-Stimulated BMDCs Promoted IL-10 Production in T Cells but Did Not Affect Regulatory T Cell Expansion Both In Vitro and In Vivo}

Having demonstrated the effects of Candida $\beta$-glucans on DC maturation and cytokine production (Figures 3-5), we next examined the orchestration of $\mathrm{T}$ cell responses by Candida $\beta$ glucan-stimulated BMDCs. To assess the direct impact of DCs on $\mathrm{T}$ cell responses, we performed an in vitro $\mathrm{DC}-\mathrm{T}$ co-culture experiment in the presence of a soluble anti-CD3 monoclonal antibody. In principle, the soluble anti-CD3 antibody binds to Fc receptors on DCs and is presented to T cells. Engagement of the soluble anti-CD3 antibody with T cells leads to transduction of the first signal into $\mathrm{T}$ cells (Clement et al., 1985; Li and Kurlander, 2010). Additional co-signals and cytokines were directly derived from Candida $\beta$-glucan-stimulated BMDCs. Using this approach, we investigated how DCs orchestrated T cell responses (Figures 6 and 7). BMDCs were stimulated with Candida $\beta$-glucans for $24 \mathrm{~h}$ and then co-cultured in vitro with $\mathrm{T}$ cells isolated from the spleens of mice in the presence of a low concentration $(30 \mathrm{ng} / \mathrm{ml})$ of soluble anti-mouse CD3 monoclonal antibody. Subsequently, levels of the $\mathrm{T}$ cell cytokines IL-2, IFN- $\gamma$, IL-17, and IL-10 were assessed by ELISA (Figure 6). As a negative control, DCs alone and T cells alone were also incubated with the soluble anti-CD3 antibody. A low dose of the soluble anti-CD3 antibody was unable to 
A

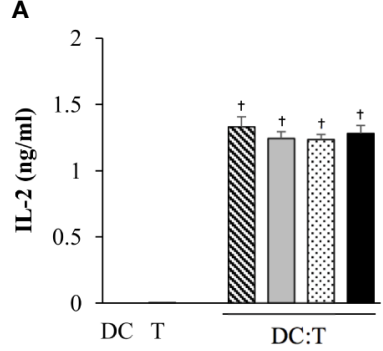

C

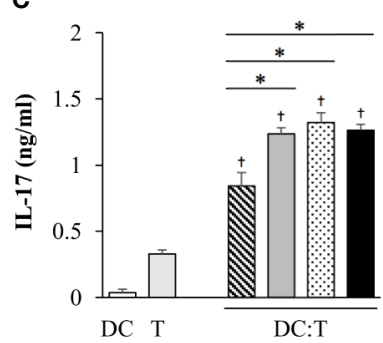

E

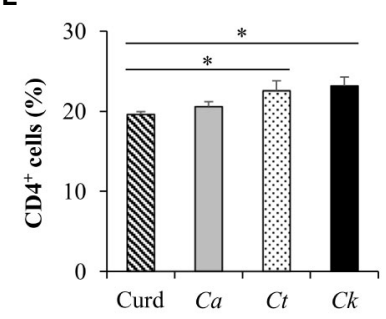

G

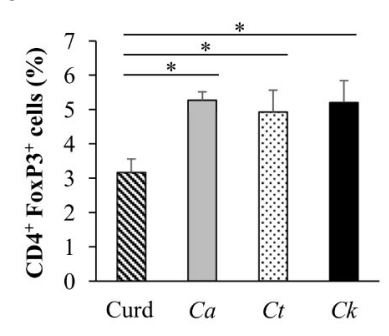

B

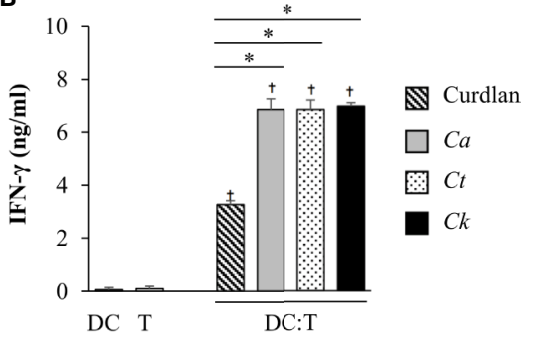

D

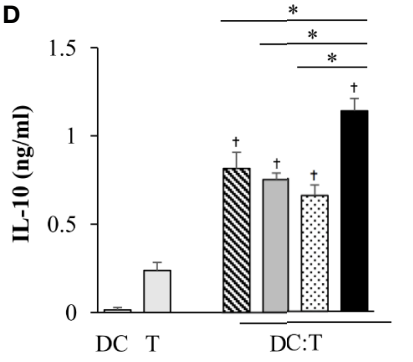

$\mathbf{F}$

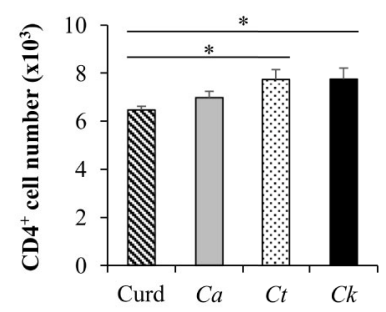

H

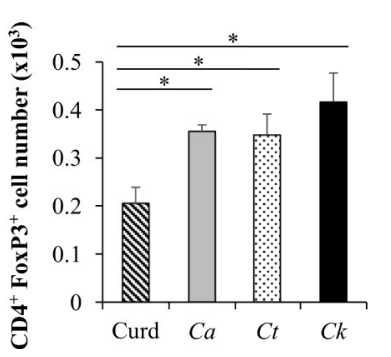

FIGURE 6 | Effects of $C$. krusei $\beta$-glucans-stimulated bone-marrow derived dendritic cell (BMDC) on cytokine production of T cells. BMDCs were stimulated with 25 $\mu \mathrm{g} / \mathrm{ml}$ of curdlan and $\beta$-glucans isolated from C. albicans, C. tropicalis, and C. krusei for $24 \mathrm{~h}$. The stimulated BMDCs were co-cultured with murine splenic T cells at a DC:T cell ratio of 1:10 in the presence of soluble anti-mouse CD3 monoclonal antibody $(30 \mathrm{ng} / \mathrm{ml})$. Levels of T cell cytokines were assessed in culture supernatants. (A) IL-2 levels were measured following $24 \mathrm{~h}$ of co-culture. (B) IFN- $\gamma$, (C) IL-17, and (D) IL-10 levels were measured following $72 \mathrm{~h}$ of co-culture. BMDCs alone and T cells alone were incubated with the soluble anti-CD3 antibody as negative controls. $n=3$; the percentages and numbers of CD4 ${ }^{+} \mathrm{T}$ cells and $\mathrm{CD}^{+}{ }^{\mathrm{FoxP}} 3^{+}$were determined following $72 \mathrm{~h}$ of co-culture by flow cytometry. $n=3$; $(\mathbf{E})$ percent and $\mathbf{( F )}$ number of $\mathrm{CD} 4^{+}$cells, $(\mathbf{G})$ percent, and $(\mathbf{H})$ number of $\mathrm{CD}^{+}{ }^{+} \mathrm{FoxP} 3^{+}$cells. data are representative of two independent experiments. ${ }^{\dagger} p<0.05$ compared with negative controls, ${ }^{*} p<0.05$. DC, BMDCs; T, T cells, Ca, C. albicans; Ct, C. tropicalis; Ck, C. krusei.

stimulate $\mathrm{T}$ cells as there was no production of a $\mathrm{T}$ cell proliferation factor, IL-2 (Figure 6A) (Spolski et al., 2018), and there was a low background of other cytokines (Figures 6B-D). Furthermore, no cytokines were released from BMDCs incubated with the soluble anti-CD3 antibody (Figures 6A-D). A commercial $\beta$-glucan, curdlan, was used as a positive control. BMDCs stimulated with curdlan and Candida $\beta$-glucans activated $\mathrm{T}$ cells in the presence of the soluble anti-CD3 antibody as shown by increased levels of IL-2. However, no difference in IL-2 levels was detected among the different $\beta$ glucans (Figure 6A). T cells co-cultured with Candida $\beta$-glucanstimulated BMDCs secreted higher levels of IFN- $\gamma$ and IL-17 than $\mathrm{T}$ cells co-cultured with curdlan-stimulated BMDCs (Figures 6B, C). We did not observe any differences in IFN- $\gamma$ and IL-17 levels between BMDCs stimulated with the three distinct Candida $\beta$-glucans. C. albicans and C. tropicalis $\beta$ glucan-stimulated BMDCs drove T cells to produce IL-10 at similar levels to those produced by $\mathrm{T}$ cells activated with curdlan- 
A

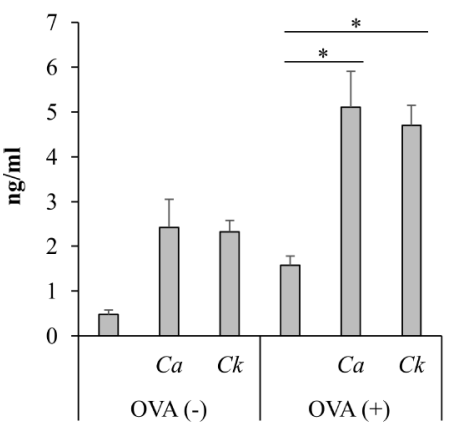

C

IL-10

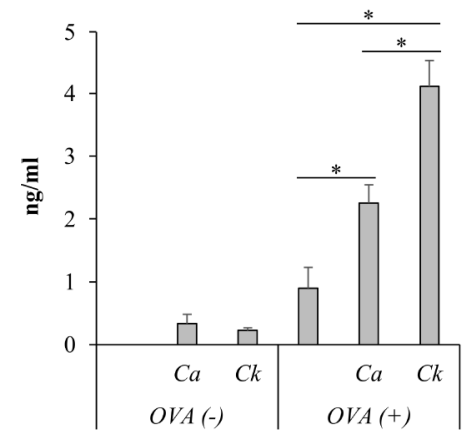

B

IL-17

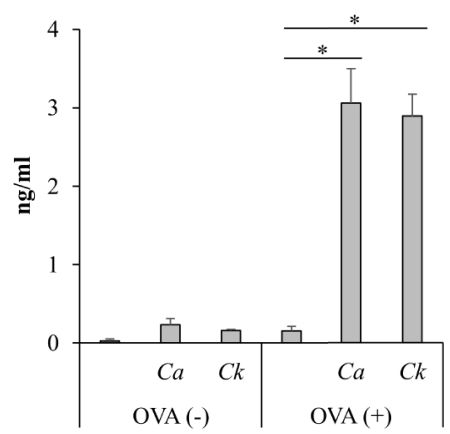

D

$\mathrm{CD4}^{+}$FoxP3 $^{+}$

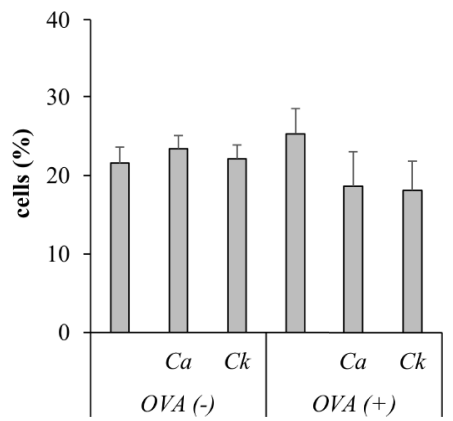

FIGURE 7 | In vivo immunization of $C$. albicans or $C$. krusei $\beta$-glucans. Mice were subcutaneously immunized with a mixture of $C$. albicans or $C$. krusei $\beta$-glucans and OVA at day 0 and day 7 . On day 14 , the draining LNs cells were isolated and were ex vivo re-stimulated with OVA for $48 \mathrm{~h}$. Culture supernatants were measured for (A) IFN- $\gamma$, (B) IL-17, and (C) IL-10 by ELISA. (D) CD4 ${ }^{+} \mathrm{FoxP}^{+}{ }^{+} \mathrm{T}$ cells were assessed by flow cytometry. $n=6$. ${ }^{*} p<0.05$. Ca, C. albicans; Ck, C. krusei.

stimulated BMDCs (Figure 6D). Strikingly, C. krusei $\beta$-glucanstimulated BMDCs predominantly induced IL-10 secretion in T cells (Figure 6D); IL-10 production by T cells was correlated with the substantial IL-10 production by $C$. krusei $\beta$-glucanstimulated BMDCs (Figure 5G).

IL-10-producing $\mathrm{T}$ cells possess regulatory function, and therefore we investigated whether FoxP $^{+}$regulatory $\mathrm{T}$ cells were also affected by C. krusei $\beta$-glucan-stimulated BMDCs. In parallel to the observation of the $\mathrm{T}$ cell cytokine responses, the proportions and numbers of $\mathrm{CD}^{+} \mathrm{T}$ cells and $\mathrm{CD} 4^{+} \mathrm{FoxP}^{+}$ regulatory $\mathrm{T}$ cells were also determined. Following $72 \mathrm{~h}$ of DC-T cell co-culture in the presence of a soluble anti-CD3 antibody, $\mathrm{CD}^{+} \mathrm{T}$ cells were analyzed by flow cytometry (Supplementary Figure S17 and Figures 6E, F). The proportions and numbers of $\mathrm{CD}^{+} \mathrm{T}$ cells among $\mathrm{T}$ cells co-cultured with $C$. tropicalis and $C$. krusei $\beta$-glucan-stimulated BMDCs were slightly higher than those among $\mathrm{T}$ cells co-cultured with curdlan and C. albicans $\beta$ glucan-stimulated BMDCs (Figures 6E, F). $\mathrm{CD}^{+} \mathrm{FoxP}^{+}$ regulatory $\mathrm{T}$ cell proportions and numbers among $\mathrm{T}$ cells activated with Candida $\beta$-glucan-stimulated BMDCs were significantly higher than those among $\mathrm{T}$ cells activated with curdlan-stimulated BMDCs (Figures 6G, H). However, BMDCs stimulated with C. albicans, C. tropicalis, and C. krusei had similar effects on $\mathrm{CD}^{+} \mathrm{FoxP}^{+}$regulatory $\mathrm{T}$ cell expansion (Figures 6G, H).

To investigate the effect of Candida $\beta$-glucans on $\mathrm{T}$ cell response in vivo, we immunized mice with a mixture of OVA and $C$. albicans or C. krusei $\beta$-glucans subcutaneously because the resident DCs in the skin could be exposed to the stimuli (Nguyen et al., 2018). After immunization, the cells from draining LNs of the immunized mice were ex vivo restimulated with OVA and followed by cytokine production and $\mathrm{CD}^{+} \mathrm{FoxP}^{+}$cell population analyses. There was no difference in the cytokines, IFN- $\gamma$ and IL-17, production in $\mathrm{T}$ cells from the mice immunized with $C$. krusei $\beta$-glucans when compared to those cytokine productions $\mathrm{T}$ cells from the mice immunized with $C$. albicans $\beta$-glucans (Figures 7A, B). Consistent to our in vitro findings, C. krusei $\beta$-glucans substantially increased IL-10 production in T cells after OVA re-stimulation (Figure 7C), and there was no increase in $\mathrm{CD}^{+} \mathrm{FoxP}^{+}$expansion in all groups (Figure 7D).

\section{Systemic Infection of Candida krusei Mediated High IL-10 Production in T Cells}

We next questioned whether $C$. krusei infection also mediates IL10 production in $\mathrm{T}$ cells, therefore, C. krusei was systemically 
infected into mice. To recapitulate systemic candidiasis in immunocompromised patient, the mice were periodically treated with dexamethasone to induce immunosuppression (Jacobsen et al., 2010), and then followed by C. krusei infection. At day 7 post-infection, the sera were collected and the splenocytes were ex vivo re-stimulated with immobilized anti-mouse CD3 to specifically activate T cells (Figure 8). The blood sera exhibited substantial decrease in IFN- $\gamma$ and increase in IL-17 levels but no alteration in IL-10 levels regardless of infection dose in C. krusei-infected group compared to the non-infected group (Figure 8A). The anti-CD3 re-activated splenocytes from C. krusei infected group did not show the change of IFN- $\gamma$ production, while the cells released high amount of IL-17. However, there were no difference in IL-17 production in the re-activated splenocytes from low dose and high dose $C$. krusei infected mice (Figure 8B). Intriguingly, the production of IL-10 in the anti-CD3 re-activated splenocytes from C. krusei infected mice were obviously enhanced in a dose dependent manner (Figure 8B). The number of $\mathrm{CD} 4^{+} \mathrm{FoxP}^{+}$cells did not expand but rather less than the control group after C. krusei infection in contrast to $\mathrm{CD} 4^{+} \mathrm{CD} 25^{+} \mathrm{FoxP}^{-}$population (Figures 8C, D). Thus, our results in systemic C. krusei infection were concordant with the observations in direct DC:T co-culture and in vivo immunization. Collectively, $C$. krusei $\beta$-glucan-stimulated BMDCs triggered substantial IL-10 production by $\mathrm{T}$ cells but did not enhance $\mathrm{CD} 4^{+} \mathrm{FoxP} 3^{+}$regulatory $\mathrm{T}$ cell expansion.

A
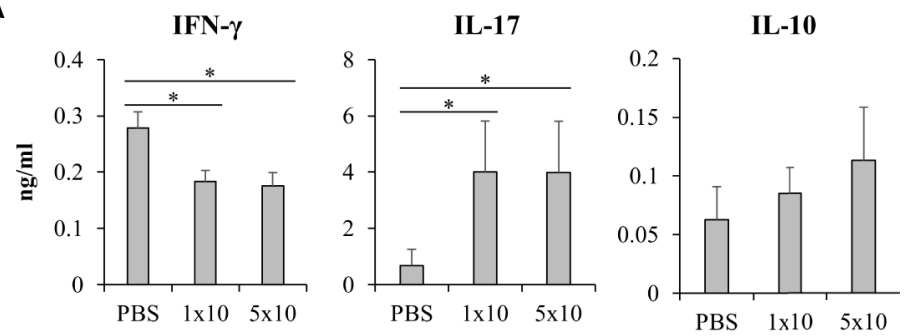

B

IFN- $\gamma$
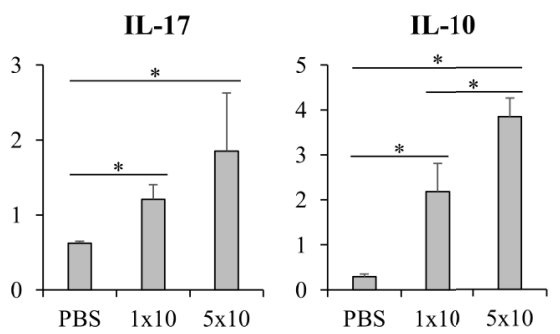

C

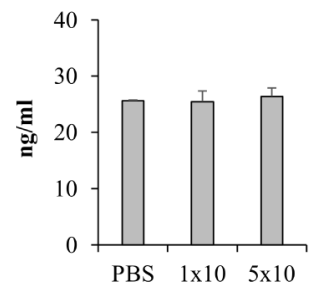

$\mathrm{CD}^{+}{ }^{+} \mathrm{CD}^{2}{ }^{+}{ }^{\mathrm{FoxP}} 3^{-}$

$\mathrm{CD}^{+}{ }^{+}{ }^{-}{ }^{-x P 3}{ }^{+}$
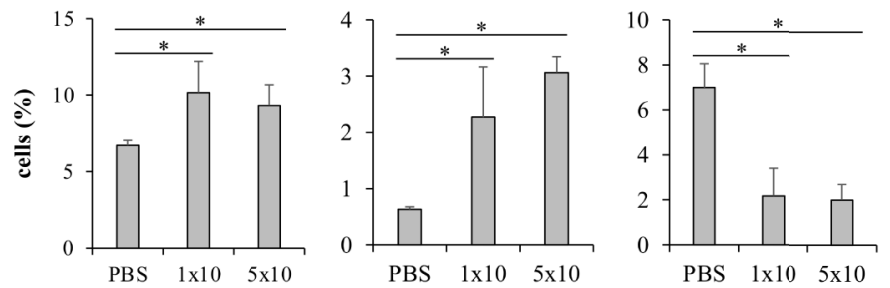

D

$\mathrm{CD}^{+}$

$\mathrm{CD}^{+}{ }^{+} \mathrm{CD}^{-}{ }^{+} \mathrm{FoxP3}^{-}$
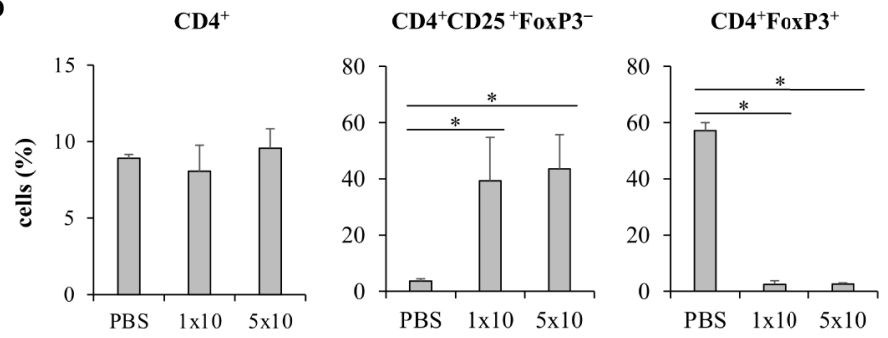

FIGURE 8 | Systemic C. krusei infection promoted IL-10 production. Mice were treated with dexamethasone to induce immunosuppression and were systemically infected with $1 \times 10^{6}$ and $5 \times 10^{6}$ of C. krusei. Serum and spleens were collected on day 7 post-infection. Splenocytes were re-stimulated with immobilized anti-CD3 for 48 h. (A) Serum cytokines. (B) Cytokines from supernatant from anti-CD3-stimulated splenocytes. (C) $T$ cells from unstimulated splenocytes. (D) $T$ cells from antiCD3 stimulated splenocytes. $n=5 .{ }^{*} p<0.05$. 


\section{Candida krusei $\beta$-Glucan Interacted With Dectin-1 Receptor in a Different Manner From C. albicans and C. tropicalis $\beta$-Glucans}

The dectin-1 receptor has been postulated to primarily recognize Candida $\beta$-glucans (Brown et al., 2003; Taylor et al., 2007), and its specific roles in recognition of $\beta$-glucans from different Candida species vary (Thompson et al., 2019). We therefore hypothesized that the differential responses of DCs to distinct Candida $\beta$-glucans may result, in part, from dissimilar interactions with dectin-1. To test this hypothesis, the dectin-1 receptor on DCs was blocked with a dectin-1 antagonist prior to Candida $\beta$-glucan stimulation, and then DC responses were assessed. Because curdlan is a well-known ligand of human and mouse dectin-1 receptor (Palma et al., 2006; Takano et al.,
2017), it was used as the positive control in all dectin-1 blockade experiments. The DC proportion and CD11c expression in the dectin-1 blocking assay were first assessed by flow cytometry (Supplementary Figure S18). Blockade of dectin-1 did not affect DC proportion or CD11c expression in BMDCs stimulated with curdlan and all Candida $\beta$-glucans (Supplementary Figures S18A and S18B). Next, we examined the effect of dectin-1 blockade on DC maturation in response to Candida $\beta$-glucan stimulation. We assessed expression levels (MFI) of DC maturation markers at $24 \mathrm{~h}$ and $48 \mathrm{~h}$ post-stimulation (Supplementary Figures S19 and S20, respectively, and Figure 9). Dectin-1 antagonism efficiently reduced CD40 and CD80 expression on BMDCs stimulated with curdlan and all Candida $\beta$-glucans (Figures 9A, B). Blockade of dectin-1 inhibited the expression of CD86 and MHC class II on
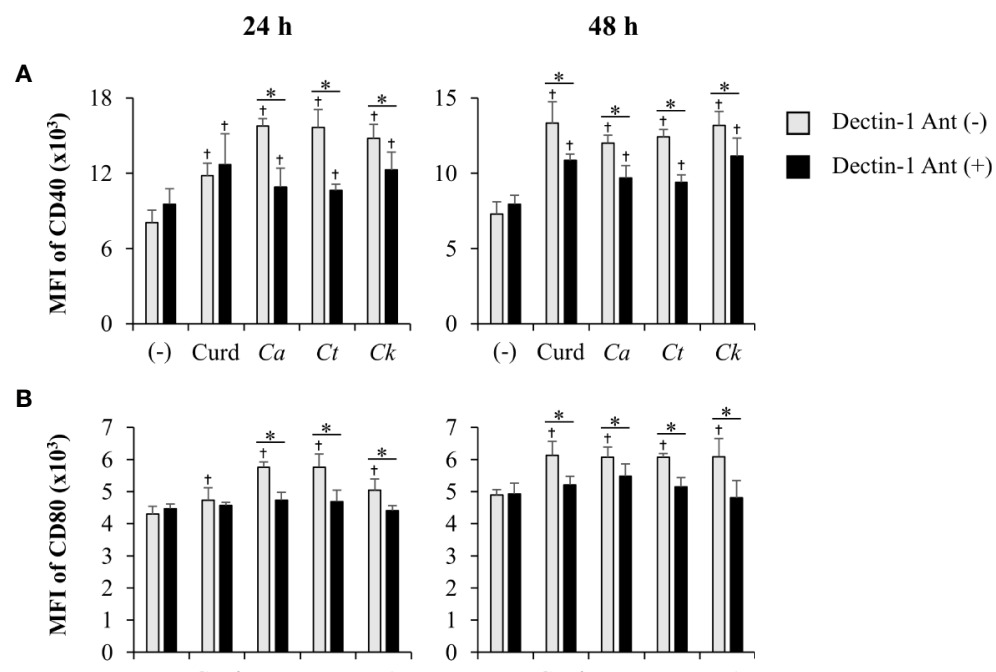

(-) Curd $\mathrm{Ca} \quad \mathrm{Ct} \quad \mathrm{Ck}$

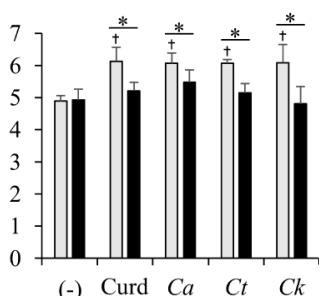

C
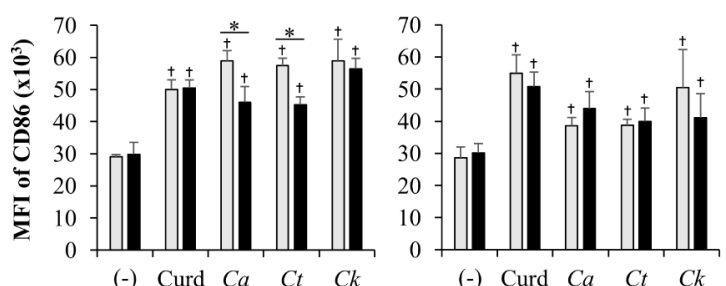

D
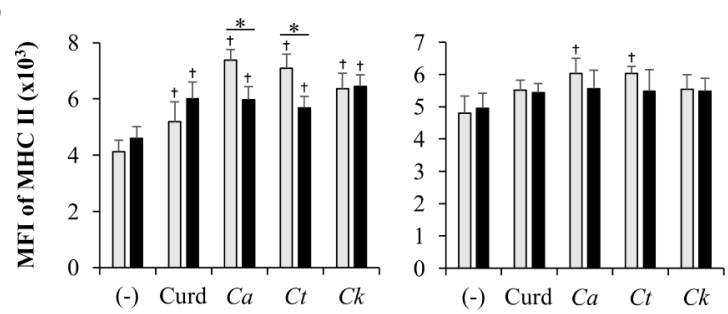

FIGURE 9 | Inhibition of dendritic cell (DC) maturation by dectin-1 blockade. Bone-marrow derived DCs (BMDCs) were pre-treated with $25 \mu \mathrm{g} / \mathrm{ml}$ of dectin-1 antagonist for $2 \mathrm{~h}$, and then the cells were stimulated with $25 \mu \mathrm{g} / \mathrm{ml}$ of curdlan and $\beta$-glucans isolated from C. albicans, C. tropicalis, and C. krusei for $24 \mathrm{~h}$ and $48 \mathrm{~h}$. The geometric mean fluorescence intensity (MFI) of DC maturation markers (A) CD40, (B) CD80, (C) CD86, and (D) MHC class II on CD11 ${ }^{+}$cells were determined using histogram analyses. $n=5$; data are representative of two independent experiments. ${ }^{\dagger} p<0.05$ compared with unstimulated BMDCs, ${ }^{\star} p<0.05$. (-), unstimulated BMDCs; Curd, curdlan; Ca, C. albicans; Ct, C. tropicalis; Ck, C. krusei. 
BMDCs stimulated with C. albicans and C. tropicalis $\beta$-glucans, but not on BMDCs stimulated with curdlan and C. krusei $\beta$ glucan (Figures 9C, D). Alterations of pro-inflammatory and anti-inflammatory cytokine responses following dectin-1 blockade were also investigated (Figure 10 and Supplementary Figure S21). Overall, inhibition of dectin-1 receptor ligation dampened production of all cytokines in curdlan- and Candida $\beta$-glucan-stimulated BMDCs at $24 \mathrm{~h}$ (Figures 10A-G) and $48 \mathrm{~h}$ (Supplementary Figure S21A-G).

To assess variation in the interactions between the three Candida $\beta$-glucans and dectin-1, we further analyzed the percent blocking of expression of DC maturation markers (Table 1) and levels of DC cytokines (Table 2). Dectin-1 antagonism less potently inhibited DC maturation in response to C. krusei $\beta$-glucan, especially at $24 \mathrm{~h}$ post-stimulation (Table
1), and least efficient blocked DC cytokine production in response to $C$. krusei $\beta$-glucan (Table 2). These results suggested that the interaction between DCs and C. krusei $\beta$ glucan may be partially dependent on dectin-1. In addition, the percent blocking of production of some cytokines in C. albicans and $C$. tropicalis $\beta$-glucan-stimulated BMDCs differed.

Coupled to dectin-1, spleen tyrosine kinase (Syk) has been well described as a crucial adaptor protein kinase of signaling pathway downstream of dectin-1 in DC anti-fungal mechanism (Whitney et al., 2014). We then investigated whether different Candida $\beta$-glucans also affect DC functions through Syk signaling pathway. BMDCs were treated with Syk inhibitor prior to Candida $\beta$-glucan stimulation. At $24 \mathrm{~h}$ and $48 \mathrm{~h}$ poststimulation, DC maturation and cytokine production were observed (Figures 11 and 12, Supplementary Figure S22,

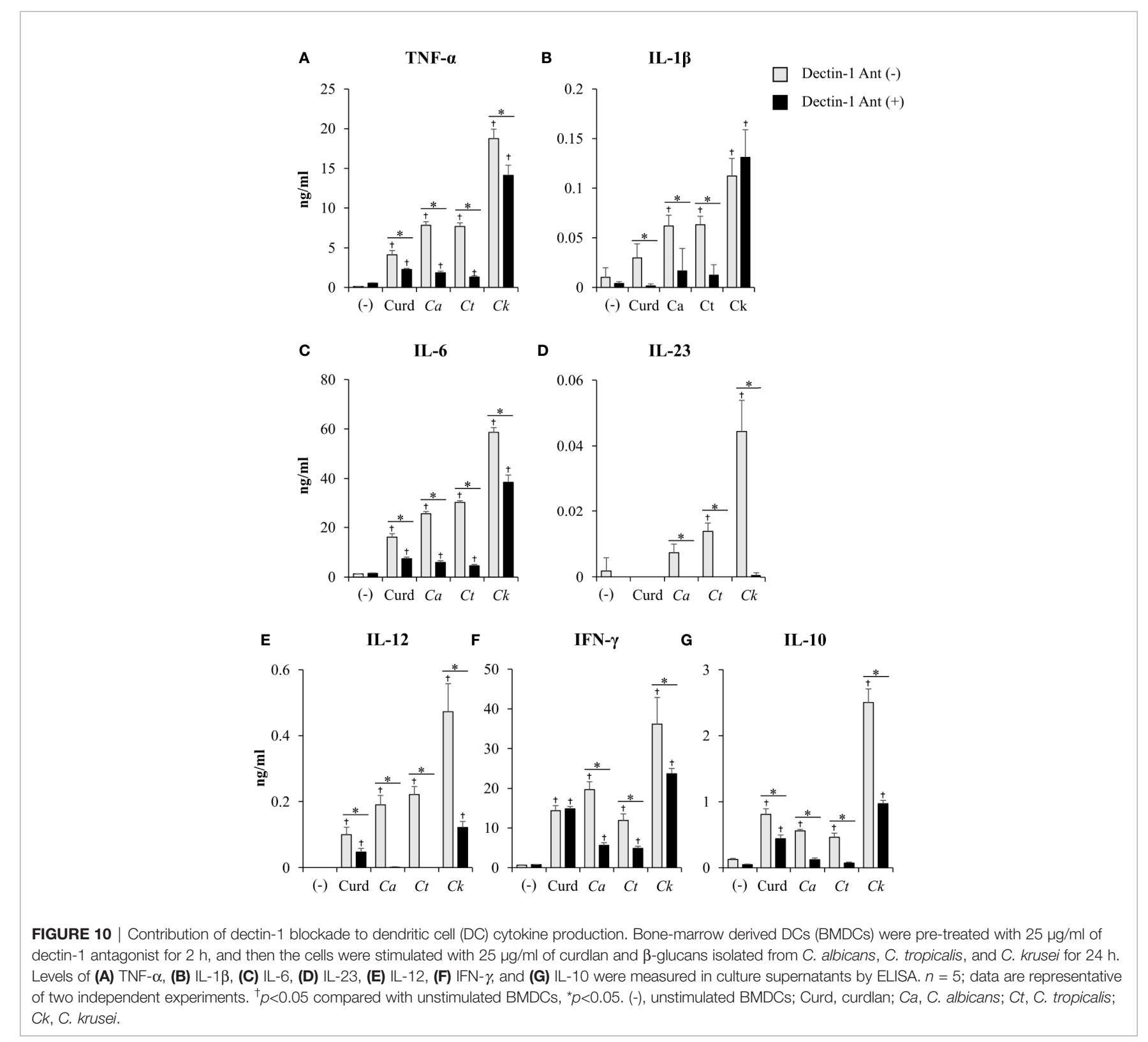


TABLE 1 | Blockade of dendritic cell (DC) maturation by dectin-1 antagonist.

$\%$ Blocking ${ }^{\star} \pm$ SD

\begin{tabular}{|c|c|c|c|c|c|}
\hline & & & & & \\
\hline & & Curdlan & C. albicans & C. tropicalis & C. krusei \\
\hline \multirow[t]{4}{*}{$24 \mathrm{~h}$} & CD40 & $2.87 \pm 3.98^{\mathrm{b}, \mathrm{c}, \mathrm{d}}$ & $30.86 \pm 9.54^{a, d}$ & $32.21 \pm 3.27^{a, d}$ & $17.05 \pm 9.65^{a, b, c}$ \\
\hline & CD80 & $3.53 \pm 2.01^{b, c}$ & $17.89 \pm 4.32^{\mathrm{a}}$ & $18.61 \pm 6.14^{\mathrm{a}}$ & $12.56 \pm 7.07$ \\
\hline & CD86 & $1.58 \pm 2.27^{\mathrm{b}, \mathrm{c}, \mathrm{d}}$ & $21.77 \pm 8.28^{a, d}$ & $21.19 \pm 4.29^{a, d}$ & $4.53 \pm 5.30^{a, b, c}$ \\
\hline & MHC class II & $0.00 \pm 0.00^{b, c, d}$ & $18.92 \pm 6.22^{a, d}$ & $25.77 \pm 5.32^{a, d}$ & $2.00 \pm 2.74^{a, b, c}$ \\
\hline \multirow[t]{4}{*}{$48 h$} & CD40 & $18.52 \pm 3.20$ & $19.42 \pm 6.89$ & $24.32 \pm 4.00$ & $15.62 \pm 9.16$ \\
\hline & CD80 & $15.03 \pm 4.22$ & $9.58 \pm 6.27$ & $15.19 \pm 4.78$ & $21.16 \pm 10.52$ \\
\hline & CD86 & $6.13 \pm 7.74$ & $1.12 \pm 2.51^{d}$ & $2.09 \pm 2.43^{d}$ & $18.57 \pm 14.82^{b, c}$ \\
\hline & MHC class II & $2.72 \pm 2.86$ & $7.84 \pm 9.18$ & $10.75 \pm 7.97$ & $3.78 \pm 3.54$ \\
\hline
\end{tabular}

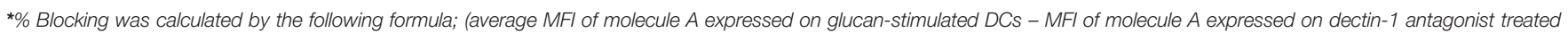

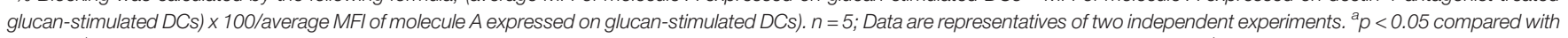
Curdlan, ${ }^{b} p<0.05$ compared with C. albicans glucan, ${ }^{c} p<0.05$ compared with $C$. tropicalis glucan, ${ }^{c} p<0.05$ compared with $C$. krusei glucan. ${ }^{d} p<0.05$ compared with $C$. krusei glucan.

TABLE 2 | Blockade of dendritic cell (DC) cytokine production by dectin-1 antagonist.

\begin{tabular}{|c|c|c|c|c|c|}
\hline & & \multicolumn{4}{|c|}{$\%$ Blocking $^{*} \pm$ SD } \\
\hline \multirow[t]{5}{*}{$24 \mathrm{~h}$} & TNF- $\alpha$ & $45.14 \pm 3.39^{b, c, d}$ & $76.37 \pm 2.53^{\mathrm{a}, \mathrm{d}}$ & $83.12 \pm 2.22^{\mathrm{a}, \mathrm{d}}$ & $24.70 \pm 6.89^{a, b, c}$ \\
\hline & IL-1 $\beta$ & $92.19 \pm 17.47^{d}$ & $73.30 \pm 36.88^{d}$ & $80.77 \pm 16.87^{d}$ & $4.02 \pm 8.98^{\mathrm{a}, \mathrm{b}, \mathrm{c}}$ \\
\hline & IL-6 & $54.53 \pm 4.55^{\mathrm{b}, \mathrm{c}, \mathrm{d}}$ & $76.98 \pm 2.60^{a, c, d}$ & $85.22 \pm 1.95^{a, b, d}$ & $34.18 \pm 4.90^{\mathrm{a}, \mathrm{b}, \mathrm{c}}$ \\
\hline & IL-23 & N.D. & $100.00 \pm 0.00$ & $100.00 \pm 0.00$ & $99.12 \pm 1.96$ \\
\hline & IL-12 & $53.02 \pm 10.84^{\mathrm{b}, \mathrm{c}, \mathrm{d}}$ & $99.58 \pm 0.94^{\mathrm{a}, \mathrm{d}}$ & $100.00 \pm 0.00^{\mathrm{a}, \mathrm{d}}$ & $74.25 \pm 3.86^{\mathrm{a}, \mathrm{b}, \mathrm{c}}$ \\
\hline \multirow[t]{6}{*}{$48 \mathrm{~h}$} & TNF- $\alpha$ & $42.62 \pm 6.14^{b, c, d}$ & $74.39 \pm 1.47^{\mathrm{a}, \mathrm{d}}$ & $81.50 \pm 0.89^{a, d}$ & $28.92 \pm 8.57^{a, b, c}$ \\
\hline & IL-1 $\beta$ & $100.00 \pm 0.00^{d}$ & $100.00 \pm 0.00^{d}$ & $100.00 \pm 0.00^{d}$ & $59.55 \pm 9.40^{a, b, c}$ \\
\hline & IL-6 & $51.43 \pm 2.61^{\mathrm{b}, \mathrm{c}, \mathrm{d}}$ & $71.45 \pm 1.76^{\mathrm{a}, \mathrm{c}, \mathrm{d}}$ & $79.72 \pm 1.70^{\mathrm{a}, \mathrm{b}, \mathrm{d}}$ & $40.52 \pm 4.67^{\mathrm{a}, \mathrm{b}, \mathrm{c}}$ \\
\hline & IL-23 & N.D. & $100.00 \pm 0.00$ & $100.00 \pm 0.00$ & $99.75 \pm 0.57$ \\
\hline & IL-12 & $63.96 \pm 7.89^{b, c, d}$ & $100.00 \pm 0.00^{a, d}$ & $100.00 \pm 0.00^{a, d}$ & $75.88 \pm 4.91^{a, b, c}$ \\
\hline & IFN- $\gamma$ & $30.30 \pm 6.18^{b, c}$ & $68.77 \pm 1.91^{a, d}$ & $66.84 \pm 1.53^{\mathrm{a}, \mathrm{d}}$ & $18.18 \pm 11.75^{b, c}$ \\
\hline
\end{tabular}

*\% Blocking was calculated by the following formula; (average MFI of cytokine A produced by glucan-stimulated DCs - MFl of cytokine A produced by dectin-1 antagonist treated glucanstimulated DCs) $\times 100$ /average MFl of cytokine A produced by glucan-stimulated DCs). $n=5$; Data are representatives of two independent experiments. ${ }^{a} p<0.05$ compared with Curdlan, ${ }^{b} p<0.05$ compared with C. albicans glucan, ${ }^{c} p<0.05$ compared with C. tropicalis glucan, ${ }^{c} p<0.05$ compared with C. krusei glucan. ${ }^{d} p<0.05$ compared with $C$. krusei glucan.

Supplementary Tables S1 and S2). Syk inhibitor could suppress DC maturation as indicated by significant reduction of CD40, CD80, CD86, and MHC class II expression as early as 24 h poststimulation (Figure 11). Expectedly, inhibition of Syk also diminished the cytokines (TNF- $\alpha$, IL-1 $\beta$, IL-6, IL-23, IL-12, IFN- $\gamma$, and IL-10) released by BMDCs stimulated with different Candida $\beta$-glucans (Figure 12 and Supplementary Figure S22). The data of Syk inhibition also showed the differential activation of BMDCs by the distinct Candida $\beta$-glucans (Supplementary Tables S1 and S2).

Having found that Candida $\beta$-glucans and dectin- 1 interactions regulated Syk-mediated cytokine production, we next questioned whether these $\beta$-glucans affect the expression of dectin-1 receptor on the DCs. To investigate this, we analyzed surface dectin-1 expression on CD11 ${ }^{+}$BMDCs after Candida $\beta$ glucan stimulation (Figure 13 and Supplementary Figure S23). C. albicans $\beta$-glucan downmodulated dectin-1 expression on BMDCs at $24 \mathrm{~h}$ and $48 \mathrm{~h}$ post-stimulation while $C$. tropicalis $\beta$-glucan did no change level of dectin-1 on BMDCs at $24 \mathrm{~h}$ but rather downmodulated the dectin-1 expression at $48 \mathrm{~h}$. Intriguingly, dectin-1 expression on BMDCs stimulation with
C. krusei $\beta$-glucans was significantly enhanced at $24 \mathrm{~h}$, and it was downmodulated at $48 \mathrm{~h}$ (Figure 13).

Collectively, these findings suggested the involvement of dectin-1 receptor and Syk signaling pathway in DC maturation and cytokine production in response to C. albicans, C. tropicalis, and $C$. krusei $\beta$-glucans, and suggested that the differential DC responses to distinct Candida $\beta$-glucans possibly resulted from dectin-1 expression and these differential interactions of the Candida $\beta$-glucans with dectin-1 were through dectin-1/Syk signaling pathway axis.

\section{DISCUSSION}

Cell wall $\beta$-glucans of $C$. albicans have been demonstrated to play a pivotal role in the induction of anti-fungal immunity (Netea et al., 2015; Camilli et al., 2018). However, our findings demonstrated that the cell wall $\beta$-glucans of C. albicans, C. tropicalis, and C. krusei have different impacts on DC immunity, which consequently influenced T cell responses. Most Candida species can undergo a yeast-tohypha transition in response to environmental conditions such as 
24 h

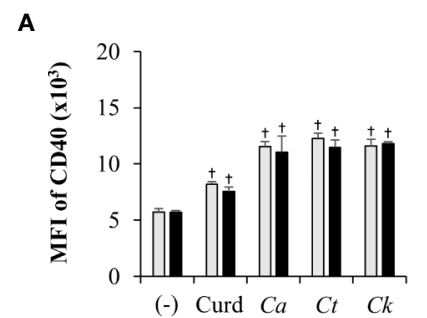

B

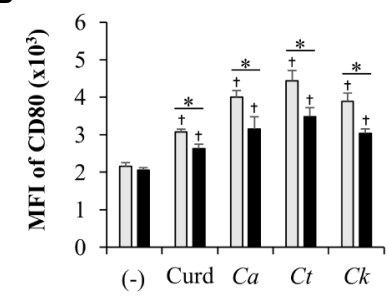

C

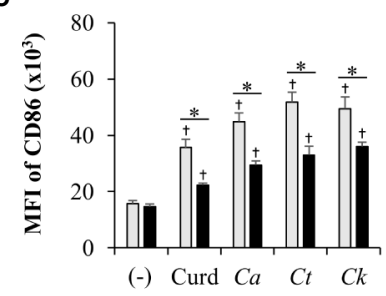

D

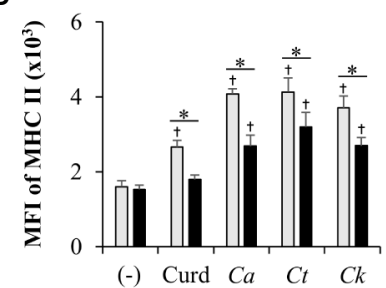

$48 \mathrm{~h}$

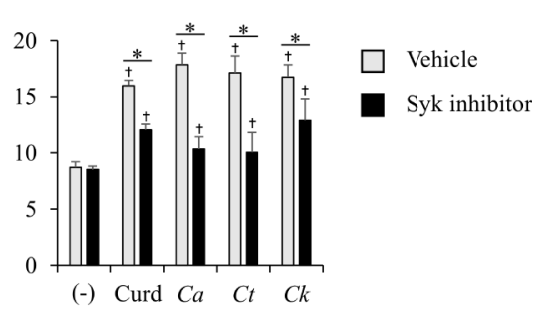

(-) Curd $\mathrm{Ca} C t \quad \mathrm{Ck}$

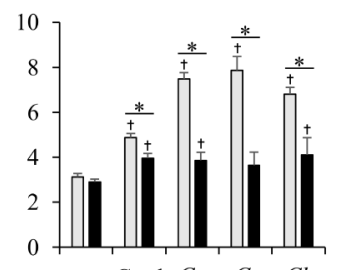

(-) Curd $\mathrm{Ca} \mathrm{Ct} C \mathrm{Ck}$
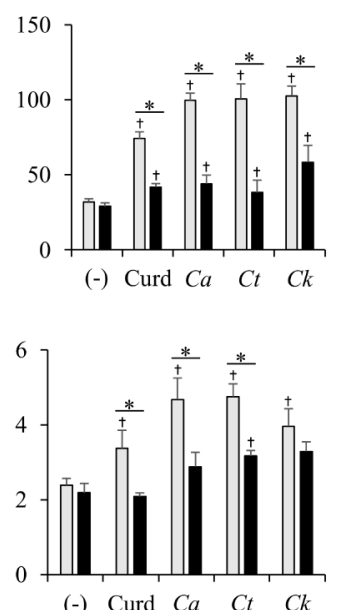

FIGURE 11 | Inhibition of dendritic cell (DC) maturation by Syk inhibitor. Bone-marrow derived DCs (BMDCs) were pre-treated with $1 \mu \mathrm{M}$ of Syk inhibitor for 30 min, and then the cells were stimulated with $25 \mu \mathrm{g} / \mathrm{ml}$ of curdlan and $\beta$-glucans isolated from C. albicans, C. tropicalis, and C. krusei for $24 \mathrm{~h}$ and $48 \mathrm{~h}$. The geometric mean fluorescence intensity (MFI) of DC maturation markers (A) CD40, (B) CD80, (C) CD86, and (D) MHC class II on CD11 ${ }^{+}$cells were determined using histogram analyses. $n=5$; data are representative of two independent experiments. ${ }^{\dagger} p<0.05$ compared with unstimulated BMDCs, ${ }^{*} p<0.05$. (-), unstimulated BMDCs; Curd, curdlan; Ca, C. albicans; Ct, C. tropicalis; Ck, C. krusei.

high temperature, $\mathrm{pH}$, and nutritional factors (Thompson et al., 2011; Lu et al., 2014). $\beta$-glucan is a major carbohydrate component of the Candida cell wall, located in the intermediate layer between mannan and chitin, and is exposed on the outer surface (Wheeler et al., 2008; Gow et al., 2011). $\beta$-glucan is masked by mannan in the cell wall of C. albicans hyphae (Bain et al., 2014; Davis et al., 2014). The yeast form in all Candida species plays a key role in the early stages of host tissue colonization (Netea et al., 2015). For these reasons, we explored the role of $\beta$-glucans in yeast cell walls, which may be linked to the physiological and immunological responses occurring in Candida-infected individuals.

Our investigations demonstrated quantitative differences in DC maturation and function in response to the cell wall $\beta$-glucans of three distinct Candida species (Figures 3-5). Several lines of evidence suggest that the differential effects of Candida $\beta$-glucans are probably related to variation in $\beta$-glucan structures. The different $\beta$-glucan structures in yeast and hyphae of $C$. albicans resulted in distinct cytokine responses in human monocyte-derived macrophages (Lowman et al., 2014). In addition, the different $\beta$ glucan contents of two distinct strains of $C$. tropicalis differentially elicited immune responses from peripheral blood mononuclear cells (Mesa-Arango et al., 2016). Although there is no direct evidence that the $\beta$-glucan structures of C. tropicalis and C. krusei differ, detection of $\beta$-glucans in the cell lysates of Candida species using $\beta$-glucan-specific antibodies reflected the inter-species diversity of $\beta$-1,6-glucan and $\beta$-1,6-glucan contents and structures (Matveev et al., 2019; Yamanaka et al., 2020). Consistently, our NMR analysis revealed the distinct $\beta$-glucan 


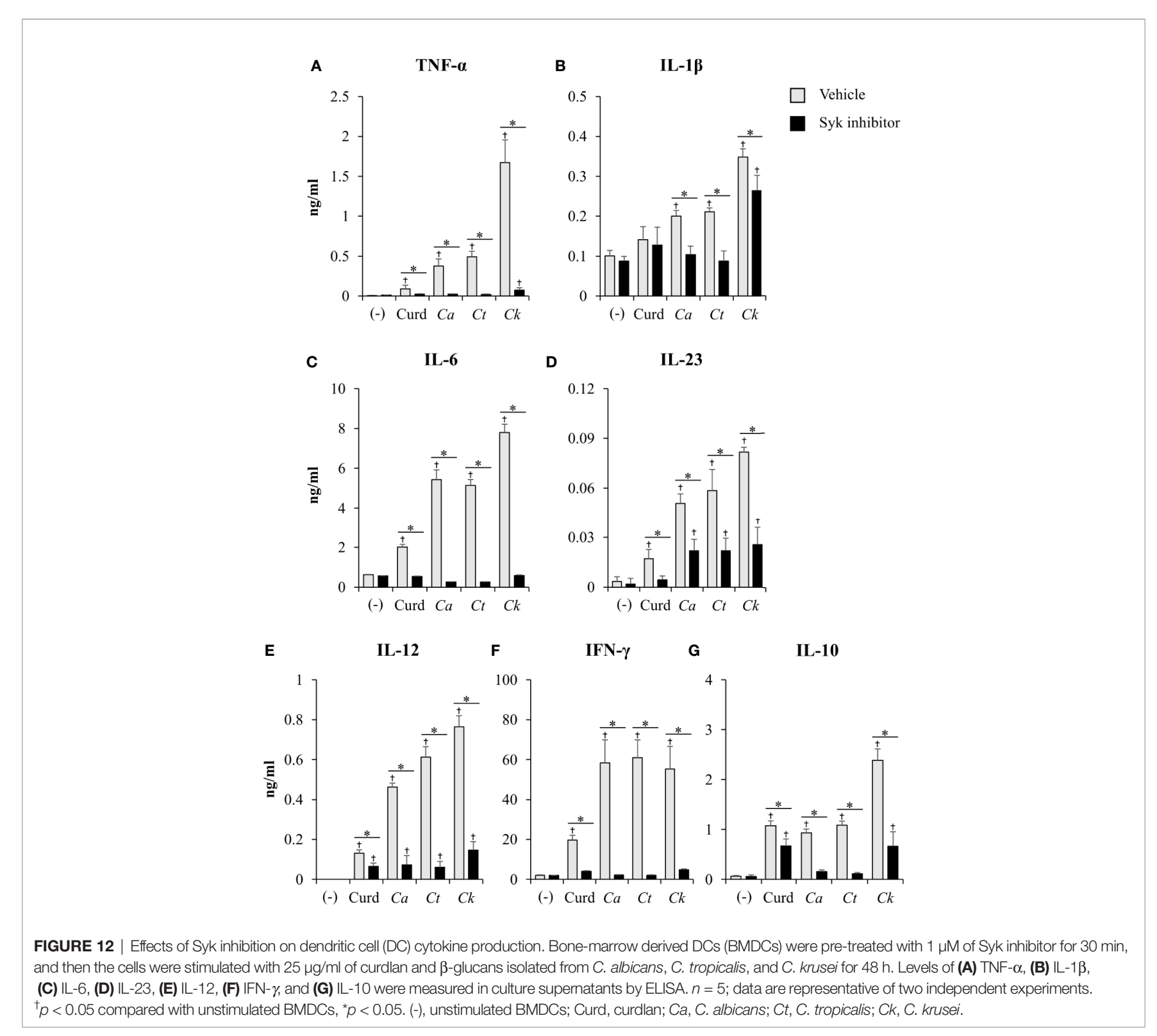

structure of C. krusei which mainly contained $\beta$-1,3-glucan (Figure 2). Meanwhile, C. albicans and C. tropicalis $\beta$-glucan composed of $\beta$-(1,3)-glucan with $\beta$-(1,6)-branching (Supplementary Figures S1 and S2) (Lowman et al., 2003b; Sukumaran et al., 2010; Lowman et al., 2014). One parameter that may also contribute to variation in immune responses is the particle size of $\beta$-glucans. As revealed by SEM, morphology of C. albicans and C. tropicalis were quite similar in shape and size whereas the morphology of C. krusei was larger and formed different shape (Figure 1). Particulate $\beta$-glucans differing in size affected the cytokine responses of human monocyte-derived DCs via regulation of dectin-1 expression (Elder et al., 2017). The resemblance in morphology and $\beta$-glucan structure of C. albicans and C. tropicalis may contribute to similarity in the immune response observed throughout this study. Presumably, structural diversity and variation in size of Candida $\beta$-glucans affected their ability to induce DC maturation and cytokine production.

The expression of CD11c was down-modulated by C. krusei $\beta$ glucans (Figure 3), regardless of DC viability (Supplementary Figure S8). Low-CD11c expressing C. krusei $\beta$-glucan-stimulated BMDCs produced high amounts of cytokines (Figure 5). Previously, DCs stimulated with several types of PRRs showed CD11c downregulation but these DCs still maintained typical cytokine production and function (Singh-Jasuja et al., 2013; Griffiths et al., 2014). In addition, lower CD11c expression following DC activation was linked with increased cytokine production (Singh-Jasuja et al., 2013). Therefore, down-modulation of CD11c may have indicated certain responses of DCs to stimuli.

DCs play a key role in effector T cell fate decisions, especially via cytokine signals (Zhou et al., 2009; Eisenbarth, 2019; Saravia et al., 


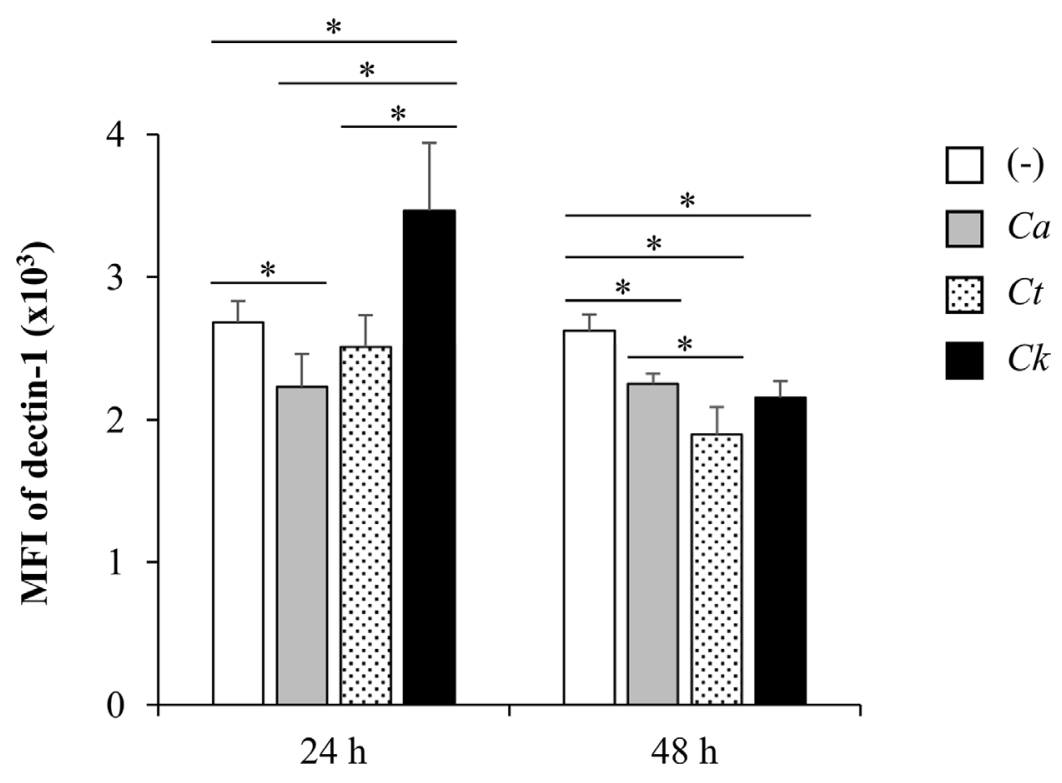

FIGURE 13 | Differential dectin-1 expression on Candida $\beta$-glucan-stimulated bone-marrow derived dendritic cells (BMDCs). BMDCs were stimulated with $25 \mu$ g/ml of $\beta$-glucans isolated from C. albicans, C. tropicalis, and C. krusei for $24 \mathrm{~h}$ and $48 \mathrm{~h}$, and the geometric mean fluorescence intensity (MFI) of dectin-1 on CD11 ${ }^{+}$ cells were determined using histogram analyses. $n=5$; data are representative of two independent experiments. ${ }^{*} p<0.05$. (-), unstimulated BMDCs; Ca, $C$. albicans; Ct, C. tropicalis; Ck, C. krusei.

2019). Our observations from DC:T cell co-culture experiments (Figure 6) and in vivo immunization of Candida $\beta$-glucans (Figure 7) demonstrated that DC functionality and T cell differentiation were differentially controlled by distinct Candida $\beta$-glucans (Figure 6). Furthermore, T helper cell differentiation was associated with cytokine production by BMDCs mediated by $\beta$ glucans. Curdlan-stimulated BMDCs were less capable of driving $\mathrm{T}$ cell differentiation (Figure 6), which corresponded with the lower ability of curdlan to induce cytokine production in BMDCs (Figure 10 and Supplementary Figure S21). As a consequence of the T cell cytokines (IL-12 and IFN- $\gamma$ for Th1; IL-1 $\beta$, IL-6, and IL-23 for Th17; IL-10 for regulatory $\mathrm{T}$ cells) produced by Candida $\beta$-glucanstimulated BMDCs (Figure 5 and Supplementary Figure S16), T cells differentiated into Th1, Th17 and regulatory T cells, which secreted IFN- $\gamma$, IL-17, and IL-10, respectively (Figure 6) (Zhou et al., 2009; Eisenbarth, 2019; Saravia et al., 2019). The increased IL10 production by $\mathrm{T}$ cells activate by $C$. krusei-stimulated BMDCs corresponded with the high IL-10 production by these BMDCs (Figure 5G and Supplementary Figure S16G); IL-10 is a key cytokine promoting the differentiation of IL-10-secreting regulatory T cells (Hsu et al., 2015; Brockmann et al., 2017; Comi et al., 2018). Although increased $\mathrm{CD}^{+} \mathrm{FoxP}^{+} \mathrm{T}$ cells were not detected among $\mathrm{T}$ cells co-cultured with $C$. krusei $\beta$-glucanstimulated BMDCs, elevated IL-10 production by $\mathrm{T}$ cells probably resulted from the increased function of FoxP $3^{+}$regulatory $\mathrm{T}$ cells and the increased expansion of FoxP3 $3^{-} \mathrm{IL}^{-10}$-secreting regulatory type 1 T cells (Schmidt et al., 2012). CD4 ${ }^{+}$effector cells (Th1, Th2, and Th17) can also produce IL-10 as a host-protective factor, but the induction of IL-10 in these cells seems to be independent of IL-10 signaling (Jankovic et al., 2010; Ng et al., 2013). In addition to the influence of IL-10 on T cell function and differentiation, substantial expression of co-stimulatory molecules, such as CD80 and CD86 is involved in the induction of IL-10-secreting T cells (Kuipers et al., 2006; Pletinckx et al., 2011). Upregulation of CD86 in BMDCs stimulated with $C$. krusei $\beta$-glucan (Figure 4C and Supplementary Figure S15A) was markedly consistent with the previous reports. Therefore, the enhanced IL-10 production by T cells may have been mediated via IL-10 and co-stimulators derived from C. krusei $\beta$ glucan-stimulated BMDCs. Even though C. krusei $\beta$-glucanstimulated BMDCs exhibited high production of Th1 and Th17 cytokines (Figure 5), IFN- $\gamma$ and IL-17 production in these T cells was not increased compared with $\mathrm{T}$ cells co-cultured with $C$. albicans and C. tropicalis $\beta$-glucan-stimulated BMDCs (Figure 6). These results could be explained by the suppressive effects of IL-10 on IFN- $\gamma$ and IL-17 production as well as Th differentiation (Wang et al., 2016; Neumann et al., 2019).

Since the mice showed the different susceptibility to Candida species (Hirayama et al., 2020), it is difficult to compare the immune response among Candida species. To determine the immune response to C. krusei, we therefore systemically infected mice with low dose and high dose of C. krusei. C. krusei also mediated IL-17 production in T cells which is similar to a previous report of $C$. albicans infection (LeibundGutLandmann et al., 2007). However, systemic C. krusei infection notably promoted IL-10 production from $\mathrm{T}$ cells in a dosedependent fashion (Figure 8). Considering of $\beta$-glucans exposed on the outer surface of the cell wall (Wheeler et al., 2008; Gow et al., 2011) and circulating $\beta$-glucans in patients with invasive candidiasis (Sims et al., 2012; Giacobbe et al., 2015), $\beta$-glucans of C. krusei may be one factor that promoted IL-10 production in $\mathrm{T}$ 
cells in murine systemic C. krusei infection. While we could observe high IL-10 production in T cells from $C$. krusei infected mice, there was no impact of $C$. krusei in regulatory T cells. The high regulatory $\mathrm{T}$ cell number in the control uninfected group may be due to the mechanism of dexamethasone in the induction of regulatory $\mathrm{T}$ cell expansion in (Engler et al., 2017). In addition, C. krusei infection showed the increased $\mathrm{T}$ cell activation $\left(\mathrm{CD} 4{ }^{+} \mathrm{CD} 25^{+} \mathrm{FoxP}^{-}\right.$) (Figures 8C, D), therefore high IL-10 production is possible mediated in a $\mathrm{C}$. krusei-specific response.

Recognition of $\beta$-glucans by dectin- 1 is important for elicitation of host protective immunity required to eradicate Candida infection (Taylor et al., 2007). Dectin-1-deficient mice exhibited increased susceptibility to systemic infections caused by various Candida species (Chen et al., 2019; Thompson et al., 2019). In addition, dectin-1 dependent immune responses differed among Candida species in association with the different levels of $\beta$-1,3-glucan exposure on the cell walls (Thompson et al., 2019). Our findings further demonstrated that dectin-1 expression on BMDCs stimulated with different Candida $\beta$-glucans varied (Figure 13), which probably led to differential DC responses (Figure 9, Figure 10, Tables 1, and Table 2). It has been well demonstrated that dectin-1 ligation activated Syk tyrosine kinase and led to anti-fungal response in DCs (Whitney et al., 2014). The inhibition of Syk also showed the differential interaction between Candida $\beta$-glucans and DCs (Figure 11, Supplementary Table 1 and 2) which supported the results of dectin-1 blockade (Figure 10, Tables 1 and 2). The differential interaction between dectin- 1 with $\beta$-glucan was previously demonstrated. The binding affinity of $\beta$-glucan to dectin-1 is influenced by polymer chain length and side-chain branching in the $\beta$-glucan structure (Adams et al., 2008). The structural conformation of $\beta$-glucan also affects its bioactivity and receptor binding efficiency (Sletmoen and Stokke, 2008; Legentil et al., 2015). In addition, the expression level of TLR2 and the cooperative action of dectin-1 and TLR2/TLR4 determine the biological response induced by the dectin-1- $\beta$ glucan interaction (Ferwerda et al., 2008; Willcocks et al., 2013; Legentil et al., 2015). Association between dectin-1 and other receptors (galectin-3 and SIGN-R1) may also be involved in dectin-1 signaling mediated by $\beta$-glucans (Esteban et al., 2011; Takahara et al., 2011).

We cannot discount the possibility that differential DC responses to distinct Candida $\beta$-glucans may be influenced by the presence of other $\beta$-glucan receptors. Complement receptor 3 (CR3) is a heterodimeric integrin consisting of two membrane proteins, $\mathrm{CD} 11 \mathrm{~b}(\alpha \mathrm{M})$ and $\mathrm{CD} 18(\beta 2)$, and is predominantly expressed on NK cells, DCs, macrophages, monocytes, and neutrophils (Goyal et al., 2018). Recognition of Candida $\beta$-glucan by CR3 also can activate innate immune cells, leading to Candida clearance (Li et al., 2019), and CR3 activation depends on the structure and composition of $\beta$-glucan (Legentil et al., 2015). Other receptors, including a lactosylceramide receptor as well as scavenger receptors, are also expressed on innate immune cells and participate in $\beta$-glucan recognition. However, little is known regarding how they interact with $\beta$-glucan (Zimmerman et al., 1998; Sato et al., 2006; Jozefowski et al., 2012).
A recent study demonstrated that dectin-1 on myeloid cells was required for C. krusei killing and induction of subsequent Th1 and Th17 anti-fungal immunity (Chen et al., 2019). In addition, dectin-1 ablation led to high fungal burdens and increased susceptibility to C. krusei infection. In contrast with a previous report, we found an immunoregulatory effect of C. krusei $\beta$-glucan. This discrepancy reflects intra-species diversity in cell wall $\beta$-glucans because different strains of C. krusei were employed in our study. Carbohydrate analyses of the cell walls of different $C$. albicans strains demonstrated variation in $\beta$-glucan structure and composition (Miura et al., 2003; Lowman et al., 2014). In addition, different C. tropicalis strains elicited distinct host immune responses (Mesa-Arango et al., 2016). In this study, a single strain of each Candida species was employed to investigate immune activation and modulation by inter-species $\beta$-glucan variation. Nonetheless, intra-species diversity of cell wall $\beta$-glucan should be considered and further investigated.

In this work, we used GM-CSF and IL-4 derived BMDCs as a platform for the in vitro study of DCs. The advantage of this culture system is cost-effectiveness and primary BMDCs can produce the results greater than DC cell line. However, BMDCs derived from GM-CSF comprise a heterogeneous population of DCs and macrophages (Helft et al., 2015; McDaniel et al., 2020). The addition of IL-4 in GM-CSF derived DC culture showed ability to limit the number of macrophages (Helft et al., 2015). Therefore, DCs may be the major population in GM-CSF and IL4 derived BMDCs in our culture system. Nonetheless, the future investigation of DC response to Candida $\beta$-glucan in other in vitro DC culture system such as FLT3L-derived BMDCs will provide more advantage and insight in DC anti-fungal immunity (Brasel et al., 2000).

Our previous study demonstrated the role of C. krusei cell wall mannan in DC-mediated Th17 immunity, which could play an important role in anti-Candida immunity (Nguyen et al., 2018). Here, we demonstrated the immunomodulatory effects of C. krusei cell wall $\beta$-glucan, which may either balance or suppress the immune response. Our findings could shed light on the different immune mechanisms responsible for defense against distinct Candida species and may be of help in the development of new diagnostic and therapeutic approaches.

\section{DATA AVAILABILITY STATEMENT}

The original contributions presented in the study are included in the article/Supplementary Material; further inquiries can be directed to the corresponding author.

\section{ETHICS STATEMENT}

All animal procedures were approved by the Chulalongkorn University Institutional Animal Care and Use Committee (IACUC) (Animal protocol 19-33-010). 


\section{AUTHOR CONTRIBUTIONS}

TD performed all dendritic cell experiments and analyzed the data. PT performed the $\mathrm{T}$ cell co-culture experiments, in vivo experiments, and analyzed the data. PPa and PPo performed the NMR analysis and analyzed the NMR data. LB performed the SEM. WS and AL assisted in the in vivo experiment. PK assisted in the in vivo data analysis and manuscript writing. PR designed and supervised the research, assisted in the data analyses, processed the data, and wrote and edited manuscript. All authors contributed to the article and approved the submitted version.

\section{FUNDING}

This work was funded by the National Research Council of Thailand, the Thailand Research Fund (TRF), TSRI fund (CU_FRB640001_01_23_1), the Ratchadapisek Sompoch Endowment Fund, the Chulalongkorn University (Health Cluster 760001-HR), and the Program Management Unit for Human Resources and Institutional Development, Research and Innovation-CU (B16F630071). The Research Unit in Integrative Immuno-Microbial Biochemistry and Bioresponsive

\section{REFERENCES}

Adams, E. L., Rice, P. J., Graves, B., Ensley, H. E., Yu, H., Brown, G. D., et al. (2008). Differential high-affinity interaction of dectin-1 with natural or synthetic glucans is dependent upon primary structure and is influenced by polymer chain length and side-chain branching. J. Pharmacol. Exp. Ther. 325 (1), 115-123. doi: 10.1124/jpet.107.133124

Bain, J. M., Louw, J., Lewis, L. E., Okai, B., Walls, C. A., Ballou, E. R., et al. (2014). Candida albicans hypha formation and mannan masking of beta-glucan inhibit macrophage phagosome maturation. mBio 5 (6), e01874. doi: 10.1128/ mBio.01874-14

Brasel, K., De Smedt, T., Smith, J. L., and Maliszewski, C. R. (2000). Generation of murine dendritic cells from flt3-ligand-supplemented bone marrow cultures. Blood 96 (9), 3029-3039. doi: 10.1182/blood.V96.9.3029

Brockmann, L., Gagliani, N., Steglich, B., Giannou, A. D., Kempski, J., Pelczar, P., et al. (2017). IL-10 Receptor Signaling Is Essential for TR1 Cell Function In Vivo. J. Immunol. 198 (3), 1130-1141. doi: 10.4049/jimmunol.1601045

Brown, G. D., Herre, J., Williams, D. L., Willment, J. A., Marshall, A. S., and Gordon, S. (2003). Dectin-1 mediates the biological effects of beta-glucans. J. Exp. Med. 197 (9), 1119-1124. doi: 10.1084/jem.20021890

Camilli, G., Tabouret, G., and Quintin, J. (2018). The Complexity of Fungal betaGlucan in Health and Disease: Effects on the Mononuclear Phagocyte System. Front. Immunol. 9, 673. doi: 10.3389/fimmu.2018.00673

Cardoso, L. S., Araujo, M. I., Goes, A. M., Pacifico, L. G., Oliveira, R. R., and Oliveira, S. C. (2007). Polymyxin B as inhibitor of LPS contamination of Schistosoma mansoni recombinant proteins in human cytokine analysis. Microb. Cell Fact. 6, 1. doi: 10.1186/1475-2859-6-1

Chen, S. M., Zou, Z., Qiu, X. R., Hou, W. T., Zhang, Y., Fang, W., et al. (2019). The critical role of Dectin-1 in host controlling systemic Candida krusei infection. Am. J. Transl. Res. 11 (2), 721-732.

Clement, L. T., Tilden, A. B., and Dunlap, N. E. (1985). Analysis of the monocyte Fc receptors and antibody-mediated cellular interactions required for the induction of $\mathrm{T}$ cell proliferation by anti-T3 antibodies. J. Immunol. 135 (1), 165-171.

Colombo, A. L., Junior, J. N. A., and Guinea, J. (2017). Emerging multidrugresistant Candida species. Curr. Opin. Infect. Dis. 30 (6), 528-538. doi: 10.1097/ QCO.0000000000000411
Nanomaterials is supported by the Ratchadapisek Sompoch Endowment Fund, Chulalongkorn University.

\section{ACKNOWLEDGMENTS}

We express our gratitude for Professor David L. Williams (Department of Surgery, James H. Quillen College of Medicine, East Tennessee State University, Johnson City, TN, USA) who kindly provided the protocols for Candida $\beta$-glucan extraction, depyrogenation and sterilization. We sincerely appreciate the Oral Biology Research Center, Faculty of Dentistry, Chulalongkorn University, for providing support in the research equipment and facilities. We thank the Edanz Group (https://en-author-services.edanzgroup.com/) for editing a draft of this manuscript.

\section{SUPPLEMENTARY MATERIAL}

The Supplementary Material for this article can be found online at: https://www.frontiersin.org/articles/10.3389/fcimb.2020. 566661/full\#supplementary-material

Comi, M., Amodio, G., and Gregori, S. (2018). Interleukin-10-Producing DC-10 Is a Unique Tool to Promote Tolerance Via Antigen-Specific T Regulatory Type 1 Cells. Front. Immunol. 9, 682. doi: 10.3389/fimmu.2018.00682

Davis, S. E., Hopke, A., Minkin, S. C. Jr., Montedonico, A. E., Wheeler, R. T., and Reynolds, T. B. (2014). Masking of beta(1-3)-glucan in the cell wall of Candida albicans from detection by innate immune cells depends on phosphatidylserine. Infect. Immun. 82 (10), 4405-4413. doi: 10.1128/ IAI.01612-14

Eisenbarth, S. C. (2019). Dendritic cell subsets in T cell programming: location dictates function. Nat. Rev. Immunol. 19 (2), 89-103. doi: 10.1038/s41577-0180088-1

Elder, M. J., Webster, S. J., Chee, R., Williams, D. L., Hill Gaston, J. S., and Goodall, J. C. (2017). beta-Glucan Size Controls Dectin-1-Mediated Immune Responses in Human Dendritic Cells by Regulating IL-1beta Production. Front. Immunol. 8, 791. doi: 10.3389/fimmu.2017.00791

Engler, J. B., Kursawe, N., Solano, M. E., Patas, K., Wehrmann, S., Heckmann, N., et al. (2017). Glucocorticoid receptor in $\mathrm{T}$ cells mediates protection from autoimmunity in pregnancy. Proc. Natl. Acad. Sci. U. S. A. 114 (2), E181-E190. doi: $10.1073 /$ pnas.1617115114

Esteban, A., Popp, M. W., Vyas, V. K., Strijbis, K., Ploegh, H. L., and Fink, G. R. (2011). Fungal recognition is mediated by the association of dectin-1 and galectin-3 in macrophages. Proc. Natl. Acad. Sci. U. S. A. 108 (34), 1427014275. doi: 10.1073/pnas.1111415108

Ferwerda, G., Meyer-Wentrup, F., Kullberg, B. J., Netea, M. G., and Adema, G. J. (2008). Dectin-1 synergizes with TLR2 and TLR4 for cytokine production in human primary monocytes and macrophages. Cell Microbiol. 10 (10), 2058 2066. doi: 10.1111/j.1462-5822.2008.01188.x

Gerbst, A. G., Grachev, A. A., Yashunsky, D. V., Tsvetkov, Y. E., Shashkov, A. S., and Nifantiev, N. E. (2013). Theoretical and Experimental Conformational Studies of Oligoglucosides Structurally Related to Fragments of Fungal Cell Wall -(13)-D-Glucan. J. Carbohydr. Chem. 32 (3), 205-221. doi: 10.1080/ 07328303.2013.793347

Giacobbe, D. R., Esteves, P., Bruzzi, P., Mikulska, M., Furfaro, E., Mesini, A., et al. (2015). Initial serum $(1,3)$-beta-D-glucan as a predictor of mortality in proven candidaemia: findings from a retrospective study in two teaching hospitals in Italy and Brazil. Clin. Microbiol. Infect. 21954 (10), e959-e917. doi: 10.1016/ j.cmi.2015.06.002 
Gow, N. A., van de Veerdonk, F. L., Brown, A. J., and Netea, M. G. (2011). Candida albicans morphogenesis and host defence: discriminating invasion from colonization. Nat. Rev. Microbiol. 10 (2), 112-122. doi: 10.1038/nrmicro2711

Goyal, S., Castrillon-Betancur, J. C., Klaile, E., and Slevogt, H. (2018). The Interaction of Human Pathogenic Fungi With C-Type Lectin Receptors. Front. Immunol. 9, 1261-1645. doi: 10.3389/fimmu.2018.01261

Griffiths, K. L., Tan, J. K., and O’Neill, H. C. (2014). Characterization of the effect of LPS on dendritic cell subset discrimination in spleen. J. Cell Mol. Med. 18 (9), 1908-1912. doi: 10.1111/jcmm.12332

Helft, J., Bottcher, J., Chakravarty, P., Zelenay, S., Huotari, J., Schraml, B. U., et al. (2015). GM-CSF Mouse Bone Marrow Cultures Comprise a Heterogeneous Population of CD11c(+)MHCII(+) Macrophages and Dendritic Cells. Immunity 42 (6), 1197-1211. doi: 10.1016/j.immuni.2015.05.018

Hirayama, T., Miyazaki, T., Ito, Y., Wakayama, M., Shibuya, K., Yamashita, K., et al. (2020). Virulence assessment of six major pathogenic Candida species in the mouse model of invasive candidiasis caused by fungal translocation. Sci. Rep. 10 (1), 3814-3823. doi: 10.1038/s41598-020-60792-y

Hsu, P., Santner-Nanan, B., Hu, M., Skarratt, K., Lee, C. H., Stormon, M., et al. (2015). IL-10 Potentiates Differentiation of Human Induced Regulatory T Cells via STAT3 and Foxo1. J. Immunol. 195 (8), 3665-3674. doi: 10.4049/ jimmunol.1402898

Inaba, K., Swiggard, W. J., Steinman, R. M., Romani, N., Schuler, G., and Brinster, C. (2009). Isolation of dendritic cells. Curr. Protoc. Immunol. Unit 3.7 (Supplement 86), 1-18. doi: 10.1002/0471142735.im0307s86

Jacobsen, I. D., Brunke, S., Seider, K., Schwarzmuller, T., Firon, A., d’Enfert, C., et al. (2010). Candida glabrata persistence in mice does not depend on host immunosuppression and is unaffected by fungal amino acid auxotrophy. Infect. Immun. 78 (3), 1066-1077. doi: 10.1128/IAI.01244-09

Jamiu, A. T., Albertyn, J., Sebolai, O. M., and Pohl, C. H. (2020). Update on Candida krusei, a potential multidrug-resistant pathogen. Med. Mycol. doi: $10.1093 / \mathrm{mmy} / \mathrm{myaa} 031$

Jankovic, D., Kugler, D. G., and Sher, A. (2010). IL-10 production by CD4+ effector T cells: a mechanism for self-regulation. Mucosal Immunol. 3 (3), 239246. doi: $10.1038 / \mathrm{mi} .2010 .8$

Jozefowski, S., Yang, Z., Marcinkiewicz, J., and Kobzik, L. (2012). Scavenger receptors and beta-glucan receptors participate in the recognition of yeasts by murine macrophages. Inflammation Res. 61 (2), 113-126. doi: 10.1007/s00011-011-0395-5

Kadosh, D., and Johnson, A. D. (2005). Induction of the Candida albicans filamentous growth program by relief of transcriptional repression: a genome-wide analysis. Mol. Biol. Cell 16 (6), 2903-2912. doi: 10.1091/ mbc.E05-01-0073

Kashem, S. W., Igyarto, B. Z., Gerami-Nejad, M., Kumamoto, Y., Mohammed, J. A., Jarrett, E., et al. (2015). Candida albicans morphology and dendritic cell subsets determine $\mathrm{T}$ helper cell differentiation. Immunity 42 (2), 356-366. doi: 10.1016/j.immuni.2015.01.008

Katiyar, S. K., and Edlind, T. D. (2001). Identification and expression of multidrug resistance-related ABC transporter genes in Candida krusei. Med. Mycol. 39 (1), 109-116.

Kim, S. H., Choi, J. K., Cho, S. Y., Lee, H. J., Park, S. H., Choi, S. M., et al. (2017). Risk factors and clinical outcomes of breakthrough yeast bloodstream infections in patients with hematological malignancies in the era of newer antifungal agents. Med. Mycol. 56 (2), 197-206. doi: 10.1093/mmy/myx038

Kingeter, L. M., and Lin, X. (2012). C-type lectin receptor-induced NF-kappaB activation in innate immune and inflammatory responses. Cell Mol. Immunol. 9 (2), 105-112. doi: $10.1038 / \mathrm{cmi} .2011 .58$

Kono, H., Kondo, N., Hirabayashi, K., Ogata, M., Totani, K., Ikematsu, S., et al. (2017). NMR spectroscopic structural characterization of a water-soluble $\beta$ $(1 \rightarrow 3,1 \rightarrow 6)$-glucan from Aureobasidium pullulans. Carbohydr. Polym. 174, 876-886. doi: 10.1016/j.carbpol.2017.07.018

Kontoyiannis, D. P. (2017). Antifungal Resistance: An Emerging Reality and A Global Challenge. J. Infect. Dis. 216 (suppl_3), S431-S435. doi: 10.1093/infdis/ jix179

Kronen, R., Lin, C., Hsueh, K., Powderly, W., and Spec, A. (2017). Risk Factors and Mortality Associated with Candida krusei Bloodstream Infections. Open Forum Infect. Dis. 4 (Suppl 1), S74-S75. doi: 10.1093/ofid/ofx163.008

Kuipers, H., Muskens, F., Willart, M., Hijdra, D., van Assema, F. B., Coyle, A. J., et al. (2006). Contribution of the PD-1 ligands/PD-1 signaling pathway to dendritic cell-mediated CD4+ T cell activation. Eur. J. Immunol. 36 (9), 24722482. doi: 10.1002/eji.200635978

Legentil, L., Paris, F., Ballet, C., Trouvelot, S., Daire, X., Vetvicka, V., et al. (2015). Molecular Interactions of beta-(1->3)-Glucans with Their Receptors. Molecules 20 (6), 9745-9766. doi: 10.3390/molecules20069745

LeibundGut-Landmann, S., Gross, O., Robinson, M. J., Osorio, F., Slack, E. C., Tsoni, S. V., et al. (2007). Syk- and CARD9-dependent coupling of innate immunity to the induction of T helper cells that produce interleukin 17. Nat. Immunol. 8 (6), 630-638. doi: 10.1038/ni1460

Li, Y., and Kurlander, R. J. (2010). Comparison of anti-CD3 and anti-CD28-coated beads with soluble anti-CD3 for expanding human T cells: differing impact on CD8 T cell phenotype and responsiveness to restimulation. J. Transl. Med. 8, 104. doi: 10.1186/1479-5876-8-104

Li, D., Bai, C., Zhang, Q., Li, Z., Shao, D., and Li, X. (2019). beta-1,3-Glucan/CR3/ SYK pathway-dependent LC3B-II accumulation enhanced the fungicidal activity in human neutrophils. J. Microbiol. 57 (4), 263-270. doi: 10.1007/ s12275-019-8298-1

Lortholary, O., Renaudat, C., Sitbon, K., Desnos-Ollivier, M., Bretagne, S., Dromer, F., et al. (2017). The risk and clinical outcome of candidemia depending on underlying malignancy. Intensive Care Med. 43 (5), 652-662. doi: 10.1007/s00134-017-4743-y

Lowman, D. W., Ferguson, D. A., and Williams, D. L. (2003a). Structural characterization of (1->3)-beta-D-glucans isolated from blastospore and hyphal forms of Candida albicans. Carbohydr. Res. 338 (14), 1491-1496. doi: 10.1016/s0008-6215(03)00169-1

Lowman, D. W., Ferguson, D. A., and Williams, D. L. (2003b). Structural characterization of $(1 \rightarrow 3)$ - $\beta$-d-glucans isolated from blastospore and hyphal forms of Candida albicans. Carbohydr. Res. 338 (14), 1491-1496. doi: 10.1016/ S0008-6215(03)00169-1

Lowman, D. W., Greene, R. R., Bearden, D. W., Kruppa, M. D., Pottier, M., Monteiro, M. A., et al. (2014). Novel structural features in Candida albicans hyphal glucan provide a basis for differential innate immune recognition of hyphae versus yeast. J. Biol. Chem. 289 (6), 3432-3443. doi: 10.1074/ jbc.M113.529131

Lu, Y., Su, C., and Liu, H. (2014). Candida albicans hyphal initiation and elongation. Trends Microbiol. 22 (12), 707-714. doi: 10.1016/j.tim.2014.09.001

Matveev, A. L., Krylov, V. B., Khlusevich, Y. A., Baykov, I. K., Yashunsky, D. V., Emelyanova, L. A., et al. (2019). Novel mouse monoclonal antibodies specifically recognizing beta-(1->3)-D-glucan antigen. PloS One 14 (4), e0215535. doi: 10.1371/journal.pone.0215535

McDaniel, M. M., Kottyan, L. C., Singh, H., and Pasare, C.. (2020). Suppression of Inflammasome Activation by IRF8 and IRF4 in cDCs Is Critical for T Cell Priming. Cell Rep. 31 (5), 107604-1-14. doi: 10.1016/j.celrep.2020.107604

Mesa-Arango, A. C., Rueda, C., Roman, E., Quintin, J., Terron, M. C., Luque, D., et al. (2016). Cell Wall Changes in Amphotericin B-Resistant Strains from Candida tropicalis and Relationship with the Immune Responses Elicited by the Host. Antimicrob. Agents Chemother. 60 (4), 2326-2335. doi: 10.1128/ AAC.02681-15

Miura, N. N., Adachi, Y., Yadomae, T., Tamura, H., Tanaka, S., and Ohno, N. (2003). Structure and biological activities of beta-glucans from yeast and mycelial forms of Candida albicans. Microbiol. Immunol. 47 (3), 173-182. doi: 10.1111/j.1348-0421.2003.tb03382.x

Netea, M. G., Gijzen, K., Coolen, N., Verschueren, I., Figdor, C., Van der Meer, J. W., et al. (2004). Human dendritic cells are less potent at killing Candida albicans than both monocytes and macrophages. Microbes Infect. 6 (11), 985989. doi: 10.1016/j.micinf.2004.05.013

Netea, M. G., Joosten, L. A., van der Meer, J. W., Kullberg, B. J., and van de Veerdonk, F. L. (2015). Immune defence against Candida fungal infections. Nat. Rev. Immunol. 15 (10), 630-642. doi: 10.1038/nri3897

Neumann, C., Scheffold, A., and Rutz, S. (2019). Functions and regulation of T cell-derived interleukin-10. Semin. Immunol. 44, 101344. doi: 10.1016/ j.smim.2019.101344

Newman, S. L., and Holly, A. (2001). Candida albicans is phagocytosed, killed, and processed for antigen presentation by human dendritic cells. Infect. Immun. 69 (11), 6813-6822. doi: 10.1128/IAI.69.11.6813-6822.2001

Ng, T. H., Britton, G. J., Hill, E. V., Verhagen, J., Burton, B. R., and Wraith, D. C. (2013). Regulation of adaptive immunity; the role of interleukin-10. Front. Immunol. 4, 129. doi: 10.3389/fimmu.2013.00129 
Nguyen, T. N. Y., Padungros, P., Wongsrisupphakul, P., Sa-Ard-Iam, N., Mahanonda, R., Matangkasombut, O., et al. (2018). Cell wall mannan of Candida krusei mediates dendritic cell apoptosis and orchestrates Th17 polarization via TLR-2/MyD88-dependent pathway. Sci. Rep. 8 (1), 17123. doi: 10.1038/s41598-018-35101-3

Padungros, P., Alberch, L., and Wei, A. (2012). Glycal Assembly by the in Situ Generation of Glycosyl Dithiocarbamates. Organic Lett. 14 (13), 3380-3383. doi: 10.1021/ol301349w

Padungros, P., Alberch, L., and Wei, A. (2014). Glycosyl Dithiocarbamates: $\beta$ Selective Couplings without Auxiliary Groups. J. Organic Chem. 79 (6), 26112624. doi: 10.1021/jo500032k

Palma, A. S., Feizi, T., Zhang, Y., Stoll, M. S., Lawson, A. M., Diaz-Rodriguez, E., et al. (2006). Ligands for the beta-glucan receptor, Dectin-1, assigned using "designer" microarrays of oligosaccharide probes (neoglycolipids) generated from glucan polysaccharides. J. Biol. Chem. 281 (9), 5771-5779. doi: 10.1074/ jbc.M511461200

Pletinckx, K., Dohler, A., Pavlovic, V., and Lutz, M. B. (2011). Role of dendritic cell maturity/costimulation for generation, homeostasis, and suppressive activity of regulatory T cells. Front. Immunol. 2, 39. doi: 10.3389/fimmu.2011.00039

Saravia, J., Chapman, N. M., and Chi, H. (2019). Helper T cell differentiation. Cell Mol. Immunol. 16 (7), 634-643. doi: 10.1038/s41423-019-0220-6

Sato, T., Iwabuchi, K., Nagaoka, I., Adachi, Y., Ohno, N., Tamura, H., et al. (2006). Induction of human neutrophil chemotaxis by Candida albicans-derived beta1,6-long glycoside side-chain-branched beta-glucan. J. Leukoc. Biol. 80 (1), 204-211. doi: 10.1189/jlb.0106069

Schmidt, A., Oberle, N., and Krammer, P. H. (2012). Molecular mechanisms of Tregmediated T cell suppression. Front. Immunol. 3, 51. doi: 10.3389/fimmu.2012.00051

Serrano, I., Luque, A., and Aran, J. M. (2018). Exploring the Immunomodulatory Moonlighting Activities of Acute Phase Proteins for Tolerogenic Dendritic Cell Generation. Front. Immunol. 9, 892. doi: 10.3389/fimmu.2018.00892

Sims, C. R., Jaijakul, S., Mohr, J., Rodriguez, J., Finkelman, M., and OstroskyZeichner, L. (2012). Correlation of clinical outcomes with beta-glucan levels in patients with invasive candidiasis. J. Clin. Microbiol. 50 (6), 2104-2106. doi: 10.1128/JCM.00773-12

Singh-Jasuja, H., Thiolat, A., Ribon, M., Boissier, M. C., Bessis, N., Rammensee, H. G., et al. (2013). The mouse dendritic cell marker CD11c is down-regulated upon cell activation through Toll-like receptor triggering. Immunobiology 218 (1), 28-39. doi: 10.1016/j.imbio.2012.01.021

Skrzypek, F., Cenci, E., Pietrella, D., Rachini, A., Bistoni, F., and Vecchiarelli, A. (2009). Dectin-1 is required for human dendritic cells to initiate immune response to Candida albicans through Syk activation. Microbes Infect. 11 (6-7), 661-670. doi: 10.1016/j.micinf.2009.03.010

Sletmoen, M., and Stokke, B. T. (2008). Higher order structure of (1,3)-beta-Dglucans and its influence on their biological activities and complexation abilities. Biopolymers 89 (4), 310-321. doi: 10.1002/bip.20920

Spolski, R., Li, P., and Leonard, W. J. (2018). Biology and regulation of IL-2: from molecular mechanisms to human therapy. Nat. Rev. Immunol. 18 (10), 648659. doi: 10.1038/s41577-018-0046-y

Sukumaran, V., Lowman, D. W., Sajeevan, T. P., and Philip, R. (2010). Marine yeast glucans confer better protection than that of baker's yeast in Penaeus monodon against white spot syndrome virus infection. Aquacult. Res. 41 (12), 1799-1805. doi: 10.1111/j.1365-2109.2010.02520.x

Suzuki, T., Omi, K., Ito, T., Takata, T., Kikutsugi, H., Fujimura, T., et al. (2006). Ethanol-induced pseudohyphal transition in the cells of Candida tropicalis: participation of phosphoinositide signal transduction. FEMS Yeast Res. 6 (2), 177-185. doi: 10.1111/j.1574-1364.2005.00020.x

Takahara, K., Tokieda, S., Nagaoka, K., Takeda, T., Kimura, Y., and Inaba, K. (2011). C-type lectin SIGNR1 enhances cellular oxidative burst response against C. albicans in cooperation with Dectin-1. Eur. J. Immunol. 41 (5), 1435-1444. doi: 10.1002/eji.200940188

Takano, T., Motozono, C., Imai, T., Sonoda, K. H., Nakanishi, Y., and Yamasaki, S. (2017). Dectin-1 intracellular domain determines species-specific ligand spectrum by modulating receptor sensitivity. J. Biol. Chem. 292 (41), $16933-$ 16941. doi: 10.1074/jbc.M117.800847

Takeuchi, O., and Akira, S. (2010). Pattern recognition receptors and inflammation. Cell 140 (6), 805-820. doi: 10.1016/j.cell.2010.01.022

Taylor, P. R., Tsoni, S. V., Willment, J. A., Dennehy, K. M., Rosas, M., Findon, H., et al. (2007). Dectin-1 is required for beta-glucan recognition and control of fungal infection. Nat. Immunol. 8 (1), 31-38. doi: 10.1038/ni1408

Thompson, D. S., Carlisle, P. L., and Kadosh, D. (2011). Coevolution of morphology and virulence in Candida species. Eukaryot. Cell 10 (9), 1173 1182. doi: 10.1128/EC.05085-11

Thompson, A., Griffiths, J. S., Walker, L., da Fonseca, D. M., Lee, K. K., Taylor, P. R., et al. (2019). Dependence on Dectin-1 Varies With Multiple Candida Species. Front. Microbiol. 10, 1800. doi: 10.3389/fmicb.2019.01800

Wang, S., Gao, X., Shen, G., Wang, W., Li, J., Zhao, J., et al. (2016). Interleukin-10 deficiency impairs regulatory $\mathrm{T}$ cell-derived neuropilin-1 functions and promotes Th1 and Th17 immunity. Sci. Rep. 6, 24249. doi: 10.1038/srep24249

Wheeler, R. T., Kombe, D., Agarwala, S. D., and Fink, G. R. (2008). Dynamic, morphotype-specific Candida albicans beta-glucan exposure during infection and drug treatment. PloS Pathog. 4 (12), e1000227. doi: 10.1371/ journal.ppat.1000227

Whitney, P. G., Bar, E., Osorio, F., Rogers, N. C., Schraml, B. U., Deddouche, S., et al. (2014). Syk signaling in dendritic cells orchestrates innate resistance to systemic fungal infection. PloS Pathog. 10 (7), e1004276. doi: 10.1371/ journal.ppat.1004276

Willcocks, S., Offord, V., Seyfert, H. M., Coffey, T. J., and Werling, D. (2013). Species-specific PAMP recognition by TLR2 and evidence for species-restricted interaction with Dectin-1. J. Leukoc. Biol. 94 (3), 449-458. doi: 10.1189/ jlb.0812390

Wuthrich, M., Deepe, G. S.Jr., and Klein, B. (2012). Adaptive immunity to fungi. Annu. Rev. Immunol. 30, 115-148. doi: 10.1146/annurev-immunol-020711074958

Yamanaka, D., Takatsu, K., Kimura, M., Swamydas, M., Ohnishi, H., Umeyama, T., et al. (2020). Development of a novel beta-1,6-glucan-specific detection system using functionally-modified recombinant endo-beta-1,6-glucanase. J. Biol. Chem. 295 (16), 5362-5376. doi: 10.1074/jbc.RA119.011851

Zhou, L., Chong, M. M., and Littman, D. R. (2009). Plasticity of CD4+ T cell lineage differentiation. Immunity 30 (5), 646-655. doi: 10.1016/j.immuni.2009.05.001

Zimmerman, J. W., Lindermuth, J., Fish, P. A., Palace, G. P., Stevenson, T. T., and DeMong, D. E. (1998). A novel carbohydrate-glycosphingolipid interaction between a beta-(1-3)-glucan immunomodulator, PGG-glucan, and lactosylceramide of human leukocytes. J. Biol. Chem. 273 (34), 22014-22020. doi: $10.1074 /$ jbc.273.34.22014

Conflict of Interest: The authors declare that the research was conducted in the absence of any commercial or financial relationships that could be construed as a potential conflict of interest.

Copyright (c) 2021 Dinh, Tummamunkong, Padungros, Ponpakdee, Boonprakong, Saisorn, Leelahavanichkul, Kueanjinda and Ritprajak. This is an open-access article distributed under the terms of the Creative Commons Attribution License (CC BY). The use, distribution or reproduction in other forums is permitted, provided the original author(s) and the copyright owner(s) are credited and that the original publication in this journal is cited, in accordance with accepted academic practice. No use, distribution or reproduction is permitted which does not comply with these terms. 